\title{
Modificación Química en Fase Sólida de Lipasa B de Candida antarctica para mejorar sus propiedades de actividad, estabilidad y enantioselectividad
}

\author{
Rodrigo Gonzalo Torres-Sáez \\ Profesor Titular, Escuela de Química, Facultad de Ciencias, Edificio "Camilo Torres", \\ Universidad Industrial de Santander, Bucaramanga, Santander, Colombia
}

\begin{abstract}
Resumen
En este trabajo, se llevó a cabo modificaciones químicas de preparaciones de lipasa B de Candida antarctica (CALB) inmovilizadas en soportes de octil-agarosa, agarosa-Bromuro Cianógeno-(BrCN) y Eupergit $\mathrm{C}$ usando diferentes compuestos químicos, por ej. Etilendiamina (EDA), anhídrido succínico (SA) y ácido 2,4,6-trinitrobencenosulfónico (TNBS). Estas modificaciones de la superficie de la enzima causó cambios en las propiedades tales como carga neta (punto isoeléctrico o balance de grupos catiónicos/aniónicos) o hidrofobicidad (solubilidad), y demostraron ser métodos prácticos para mejorar el funcionamiento del biocatalizador (estabilidad, actividad y enantioselectividad). Estas alteraciones en las propiedades de la enzima por modificación química podría ser debida a cambios en la estructura de la forma activa de CALB. De esta manera, la modificación química en fase sólida de lipasas inmovilizadas podría convertirse en una herramienta poderosa en el diseño de librerías de lipasas con propiedades muy diferentes.
\end{abstract}

Palabras claves: Lipasa, Candida antarctica B, enzimas, modificación química.

Chemical Modification in Solid Phase Chemistry of Lipase B from Candida antarctica for improving its properties of activity, stability and enantioselectivity

\begin{abstract}
In this work, it was carried out chemical modifications of Candida antarctica lipase B (CALB) preparations immobilized on octyl-agarose, $\mathrm{BrCN}$-agarose and Eupergit-C supports using different chemical compounds, e.g. ethylenediamine (EDA), succinic anhydride (SA) and 2,4,6-trinitrobenzensulfonic acid (TNBS). These modifications of the enzyme surface caused changes in physical properties such as net charge (isoelectric point or balance of cationic/anionic groups) or hydrophobicity (solubility), and proved to be practical methods to enhance the biocatalyst performance (stability, activity and enantio-selectivity). These alterations in enzyme properties by chemical modification should be due to changes in the structure of the active form of CALB. Therefore, solid phase chemical modification of immobilized lipases may become a powerful tool in the design of lipase libraries with very different properties.
\end{abstract}

Key words: Lipase, Candida antarctica B, enzymes, chemical modification.

\section{Introdución}

Las enzimas son biocatalizadores que llevan a cabo diversos procesos químicos bajo condiciones suaves de reacción. Sin embargo, las enzimas se han seleccionado a través de procesos naturales de evolución, lo cual ha generado que la gran mayoría operen generalmente en condiciones ambientales suaves de reacción. Esta situación ha limitado mucho su aplicación en procesos industriales que utilizan condiciones drásticas de reacción. Por esta razón, se requiere la estabilización funcional de las enzimas en condiciones diferentes a las fisiológicas, de manera de ampliar su espectro de acción en procesos de transformación de sustratos que requieren condiciones noconvencionales de $\mathrm{pH}$, temperatura, presión, sales, solventes orgánicos, etc. (Cantone et al., 2007; Durand et al., 2007; Sheldon, 2005).

En general, las enzimas no cumplen con todos los requerimientos de un biocatalizador industrial, por lo que requieren del mejoramiento de una o más de sus propiedades

\section{Correspondencia:}

Rodrigo Gonzalo Torres-Sáez, rtorres@uis.edu.co

Recibido: 6 de mayo de 2014

Aceptado: 16 de novimbre de 2014 
funcionales antes de su implementación en un proceso enzimático o quimio-enzimático (Shoemaker et al., 2003; Polizzi et al., 2007; Meyer, 2006). La modificación de las propiedades bioquímicas de las enzimas se pueden lograr usando diferentes tipos de herramientas disponibles en ingeniería de proteínas. Por ejemplo, el desarrollo de técnicas metagenómicas ha permitido el descubrimiento y acceso a genes con nuevas funciones enzimáticas a partir de microorganismos extremófilos o no-cultivables (Ferrer et al., 2007). Se han usado también técnicas de DNA recombinante para el clonamiento y sorebexpresión de enzimas (Samuelson, 2011; Smith, 1996), mutagénesis sitio dirigida y métodos de evolución molecular (Kurtovic \& Mannervik, 2009; Schmidt et al., 2009; Reetz, 2007; Jäckel et al., 2008), lo cual ha hecho posible manipular prácticamente cualquier propiedad enzimática.

Por otro lado, se han desarrollado muchos avances en el diseño de nuevos soportes y protocolos de inmovilización de enzimas para el mejoramiento de las propiedades bioquímicas que incluyen actividad, selectividad y estabilidad (Hernández \& Fernández-Lafuente, 2011; Zhang et al., 2005; Rodrigues et al., 2013). Tradicionalmente, las herramientas de ingeniería de proteínas han sido usadas de forma independiente para mejorar el funcionamiento de las enzimas. Sin embargo, el uso conjunto de diferentes estrategias genéticas y químicas han mostrado un efecto sinérgico (Rodrigues et al., 2011), donde por ejemplo, las propiedades de enzimas genéticamente modificadas pueden ser posteriormente mejoradas mediante inmovilización en soportes (Vallin et al., 2010; Ortiz-Soto et al., 2009; Van Loo et al., 2009; Chiang et al., 2008) o modificación química (Gron et al., 1990; Matsumoto et al., 2002; Davis et al., 1999); por otro lado, las enzimas modificadas de forma química pueden ser posteriormente estabilizadas por inmovilización enzimática (Forde et al., 2010a; Forde et al., 2010b). Existen muchos ejemplos de uso conjunto de diferentes herramientas para mejorar el funcionamiento de las enzimas (Ulbrich-Hoffman et al., 1999; Mansfeld et al., 1999; Wynn \& Richards, 1993).

\subsection{Modificación Química de Enzimas}

Aunque la modificación genética de enzimas ha desplazado a la modificación de enzimas como estrategia de ingeniería de proteínas, la modificación química aún permanece como un método efectivo para la estabilización de proteínas (Tyagi and Gupta, 1998; Davis, 2003; O`Fágáin, 2003). La modificación química es generalmente no-sitio dirigida. Sin embargo, es posible dirigir las modificaciones a grupos únicos de la estructura proteica como por ej. Reacciones de Cicloadición Diels-Alder (Palomo, 2010) e intercambio de tioles, con grupos aminos terminales. Por otro lado, se ha logrado la modificación con grupos tioles de proteínas que contenían sólo un residuo de cisteína en la superficie de la proteína (natural o introducido vía mutagénesis sitio dirigida) (Wynn and Richards, 1993; De Santis \& Jones, 1999; Chalker et al., 2009). A pesar del enorme poder de la manipulación genética, la modificación química tiene algunas ventajas que la distinguen (Baslé et al., 2010; Rodrigues et al., 2011). Por ejemplo, la modificación química permite la introducción de un amplio rango de grupos químicos a la estructura de la enzima (Davis, 2003), no requiere predicción de la estructura de la proteína, constituye un método rápido (comparado con la modificación genética) y se puede realizar con la enzima en su estructura nativa. Si la modificación es llevada a cabo en fase sólida (usando enzimas inmovilizadas), existen ventajas adicionales (Rodrigues et al., 2011), tales como un mayor control de la modificación química minimizando interacciones indeseables proteína-proteína. Además, el uso de enzimas inmovilizadas facilita el uso de medios no convencionales (por ej. Medios orgánicos anhidros) y puede simplificar el número de pasos de la modificación química de enzimas (Rodrigues et al., 2011; Fernández-Lafuente, 2009). El uso de enzimas estabilizadas por vía multipuntual o de múltiples subunidades también limita la extensión de la inactivación enzimática que puede resultar de los procesos de modificación química (Rodrigues et al., 2011; Fernández-Lafuente et al., 1992).

La modificación química de una enzima puede ser usada para cambiar las propiedades globales de la superficie de la enzima o para la modificación de residuos claves (Rodrigues et al., 2011; O'Fágáin, 2003; Davis, 2003). Por ejemplo, se modificaron 17 residuos de lisina (Lys) de alfa-amilasa de Bacillus amyloquefaciens con anhídrido citracónico, estabilizando significativamente la enzima cuando se sometió a altas temperaturas (un efecto no encontrado a bajas temperaturas) (Khajeh et al., 2001). Se ha llevado a cabo la modificación de enzimas con polietilenglicol o detegentes, que mejoran la solubilidad y estabilidad de las enzimas en medios orgánicos (Gupta and Roy, 2004). De igual manera, la modificación química puede usarse para modular las propiedades catalíticas de las enzimas. Sin embargo, los efectos de la modificación en las propiedades enzimáticas son difíciles de predecir (Torchilin et al., 1997; Rodrigues et al., 2011).

La estrategia de modificación química se puede usar también para generar entrecruzamiento covalente entre diferentes grupos de la superficie de la enzima (Rodrigues et al., 2011; Wong \&Wong, 1992). Los entrecruzamientos suceden entre diferentes elementos de una proteína, y favorecerán generalmente la rigidez estructural de la enzima incrementando su estabilidad con respecto a agentes que inducen cambios conformacionales (tales como agentes caotrópicos o calor). El entrecruzamiento intramolecular no es necesariamente sencillo. Por ej. El agente entrecruzante debe tener una longitud apropiada (Torchilin et al., 1979), y cuando se usan reactivos homo-bifuncionales, podría generarse una fuerte 
competencia entre el entrecruzamiento intramolecular, la modificación uni-puntual y el entrecruzamiento intermolecular (Rodrigues et al., 2011; Fernández-Lafuente, 2009). A su vez, el uso de polímeros multifuncionales simplifica la generación de enlaces de múltiples entrecruzamientos y está menos limitado por las restricciones de distancia o competición por la modificación uni-puntual. Sin embargo, la flexibilidad y longitud molecular de los polímeros limita el grado de rigidificación de la proteína que puede ser obtenida mediante este tipo de moléculas (Betancor et al., 2006). Por el contrario, los reactivos multifuncionales han prevenido efectivamente la disociación de proteínas multiméricas y oligoméricas, o complejos multiproteicos (Rodrigues et al., 2011; Fernández-Lafuente, 2009).

\subsection{Lipasas como Biocatalizadores}

Las lipasas están entre las enzimas más ampliamente usadas en biocatálisis (Gandhi, 1997; Pandey et al., 1999), debido a que son capaces de llevar a cabo reacciones de biotransforamción con una alta selectividad y especificidad, y pueden ser usadas en diferentes medios de reacción (Peterson et al., 2007; Reetz, 2002; van Rantwijk et al., 2003; Itoh, 2009: Jaeger \& Reetz, 1998). La aplicación de lipasas en procesos de biotransformación en diversos campos industriales, se ha debido esencialmente a la gran actividad que exhibe en medios acuosos y alta especificidad y selectividad hacia el sustrato sobre el cual actúan (Pollard\&Woodley, 2007; Woodley, 2008; Schmid et al., 2001; Straathof et al., 2002). De esta manera, las lipasas han sido utilizadas tanto en la industria de alimentos, biocombustibles y química fina (Berglund, 2001; Fjerbaek et al., 2009; Aravindan et al., 2007; Adlercreutz, 2013; Iwasaki \& Yamane, 2000; Stonkus et al., 2001).

Desde el punto de vista funcional, las lipasas (triacil glicerol acil-hidrolasas EC 3.1.1.3) constituyen un grupo de enzimas pertenecientes a la familia de las serina-hidrolasas que se encuentran ampliamente distribuidas en la naturaleza y catalizan la hidrólisis de triglicéridos para la formación de ácidos grasos y glicerol (Figura 1) (Martinelle et al., 1995; Svendsen, A., 2000; Sharma et al., 2011).

Las lipasas son consideradas las enzimas con mayor aplicación en síntesis orgánica debido a que exhiben alta especificidad, regio y enantioselectividad. Además, catalizan una gran variedad de reacciones químicas, entre las que se incluyen: reacciones de hidrólisis; reacciones de esterificación selectiva entre ácidos y alcoholes (Ortega et al., 2012; Wang et al., 2013); reacciones de trans-esterificación catalizando el intercambio de grupos acilo, ya sea entre un éster y un ácido carboxílico (acidólisis) (Xiong et al., 2012; Ray et al., 2013), un éster y otro éster (inter-esterificación), o un éster y un alcohol (alcohólisis) (Santaniello et al., 2006; GotorFernández et al., 2006a; Ahmed et al., 2012). Además, las lipasas catalizan reacciones de aminólisis para síntesis de amidas, tanto racémicas como ópticamente activas (Gotor-Fernández et al., 2006a; Prechter et al., 2012) y la hidrazinólisis selectiva de ésteres para la formación de hidrazinas (Hacking et al., 2000) (Ver Figura 2).

\subsection{Estructura tridimensional (3D) de lipasas}

En los años 90, se determinó la estructura 3D de diferentes lipasas mediante técnicas cristalográficas, identificándose en general una configuración de tipo $\alpha / \beta$ hidrolasa (Derewenda et al., 1992; Grochulsky et al., 1993; Ericsson et al., 2008). Además, se encontró que el centro activo de las lipasas estaba conformado por una triada catalítica constituida por residuos de serina (Ser), histidina (His) y otro aminoácido que suele ser ácido aspártico (Asp) o ácido glutámico (Glu), localizado en una cavidad conocida como hueco hidrofóbico de la enzima.

De igual forma, se determinó que en la mayoría de las lipasas existe un elemento móvil, el cual es conocido como "lid" o tapadera, conformado por una o dos estructuras alfa-hélice cortas, unidas al cuerpo de la lipasa mediante elementos

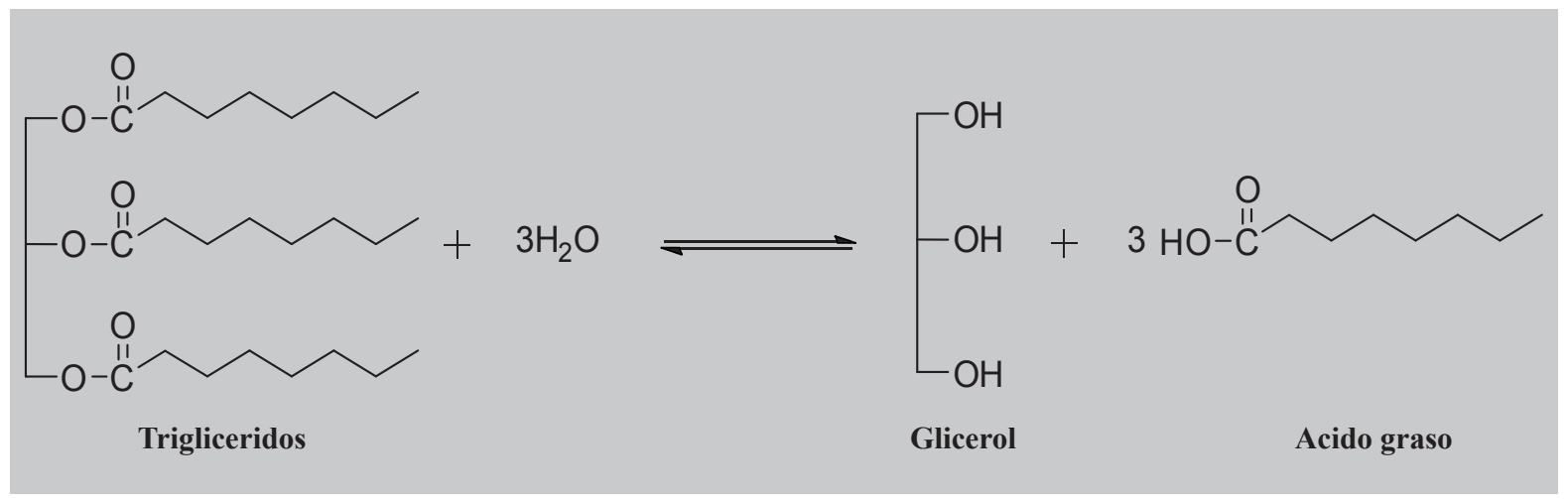

Figura 1. Función biológica de las lipasas. Hidrólisis de triglicéridos in vivo. Se ejemplifica la reacción de hidrólisis de tri-octil-glicerol por lipasa microbiana. 


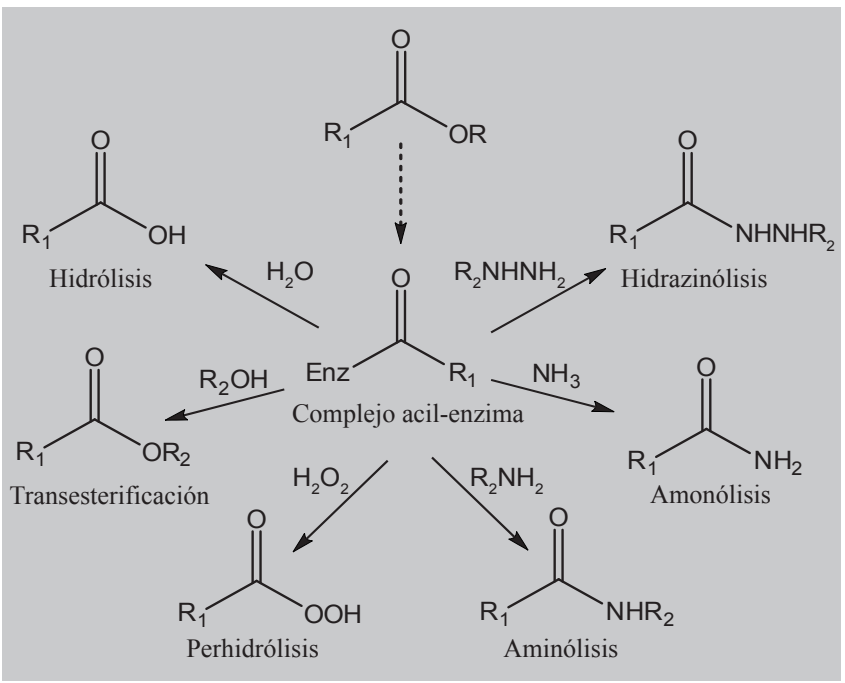

Figura 2. Reacciones catalizadas por lipasas in vitro.

flexibles. Brzozowski $\boldsymbol{e t}$ al., (1991) y Uppenberg $\boldsymbol{e t}$ al., (1994), confirmaron y demostraron la existencia del lid sobre el sitio activo de las lipasas a través del estudio de la formación de complejos enzima-inhibidor. La información acerca de la conformación estructural de las lipasas permitió establecer que en presencia de medios acuosos homogéneos, la lipasa cristaliza con el centro activo totalmente aislado del medio de reacción por la tapadera (flat o lid), haciendo inaccesible la entrada de los sustratos (conformación cerrada) hacia el sitio activo. Esta cadena polipeptídica presenta en su cara interna una serie de residuos hidrofóbicos que interaccionan con las zonas hidrofóbicas que rodean al sitio activo de las lipasas (Bastida et al., 1998).

Por el contrario, cuando la enzima se cristaliza en presencia de interfases hidrofóbicas se obtiene una conformación totalmente distinta, en la cual la tapadera se desplaza del centro activo producto de la interacción entre puentes salinos y puentes de hidrógeno con otra zona de la superficie de la lipasa, dejando libre el centro activo de la enzima (conformación abierta) (Bastida et al., 1998; Reis et al., 2008; Reis et al., 2009; Rehm et al., 2011). La figura 3 muestra las distintas conformaciones de las lipasas.

Las singulares características estructurales de las lipasas sugieren que la presencia del lid es un determinante estructural y funcional de la actividad y selectividad de esta enzima en la catálisis de diferentes reacciones de biotransformación en química orgánica (Overbeeke et al., 2000; Reetz, 2002; Barros et al., 2010; Casas-Godoy et al., 2012). En 2006, Secundo et al. investigaron sobre la influencia del "lid" en las propiedades biocatalíticas de las lipasas. En el estudio, se modificaron por mutagénesis algunos aminoácidos de la secuencia del lid de tres lipasas recombinantes: Candida

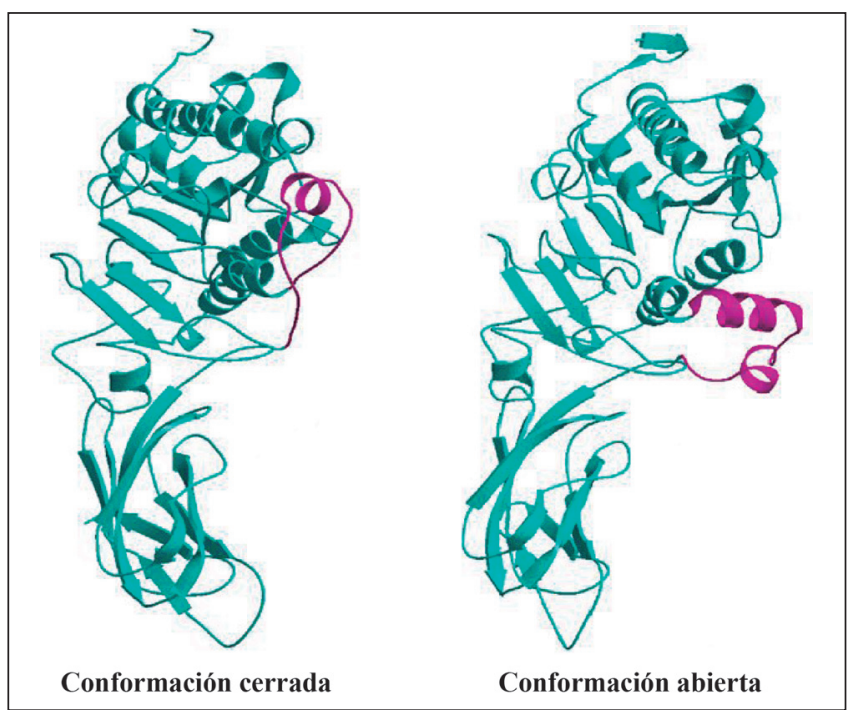

Figura 3. Conformaciones estructurales de la lipasa B de Candida antarctica. Tomada de Protein Data Bank, código de acceso 1TCB.

rugosa (CRL), Pseudomonas fragi (PFL) y Bacillus subtilis (BSLA). Las lipasas modificadas presentaron menor actividad y selectividad en reacciones de esterificación en solventes orgánicos. Los resultados obtenidos soportan fuertemente la idea de la importancia que tiene el lid en la modulación, no sólo de la actividad, sino también en la especificidad, enantio-selectividad y estabilidad de las lipasas.

Recientemente, Yu et al., 2012, investigaron el efecto de la flexibilidad conformacional del lid sobre la actividad catalítica y estabilidad térmica de la lipasa Rhizopus chinensis. En este caso, se indujo la formación de un enlace de puente disulfuro en la región del lid, con el fin de limitar su movilidad. Los resultados obtenidos mostraron que la enzima mutante es 12 veces más termo-estable que la enzima no mutada. A su vez, esta modificación estructural no efectó el rendimiento catalítico de la lipasa. De acuerdo con lo anterior, a la hora de utilizar las lipasas en reacciones de química orgánica, es preciso considerar algunas peculiaridades de su mecanismo de activación interfacial, para lo cual resulta indispensable el estudio de la estructura molecular.

\subsubsection{Lipasa B de Candida antarctica (CALB)}

La CALB es una isoenzima que proviene de la levadura Candida antarctica. Fue aislada por primera vez en la Antártida cuando se examinaban enzimas activas en condiciones extremas. Actualmente, es obtenida a partir de procesos de clonación y sobre-expresión en en el hongo Aspergillus oryzae (Kirk et al., 2002).

La lipasa B de Candida antarctica presenta un peso molecular de $33 \mathrm{kDa}$ y un punto isoeléctrico de 6.0. Exhibe una especificidad posicional de tipo $S n-3$ en la hidrólisis de 


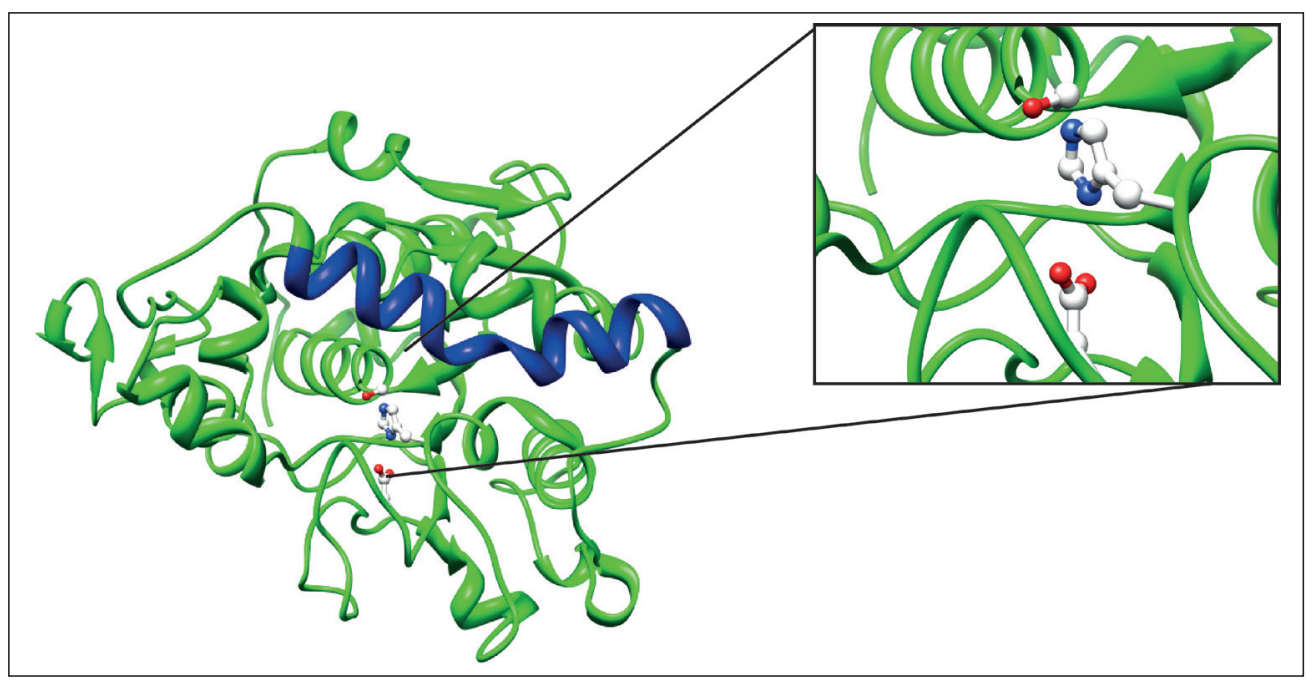

Figura 4. Estructura Lipasa B de Candida antarctica. Tomada de protein Data Bank (1LBT.pdb). Sofware de visualización Chymera.

triglicéridos (Kirk et al., 2002). La secuenciación de CALB ha revelado que su estructura primaria está formada por 317 residuos, los cuales se pliegan en un modelo de $\alpha / \beta$ hidrolasa (Ver Figura 4). Su sitio activo consiste de una triada catalítica de serina, histidina y aspartato. La entrada a dicho sitio activo se encuentra restringida por una $\alpha$-hélice hidrofóbica (lid) muy importante en la especificidad y estereoespecíficidad de la enzima frente a diferentes sustratos (Uppenberg et al., 1994).

CALB es ampliamente usada como biocatalizador debido a la aceptable regioselectividad y enantioselectividad frente a alcoholes, aminas, ésteres y ácidos racémicos (Anderson et al., 1998; Kirk et al., 2002; Gotor-Fernández et al., 2006b; Juhl et al., 2010; Kolodziejska et al., 2012). CALB es provista por Novozymes in forma libre e inmovilizada (Novozym 435), y es producida en Aspergillus niger, presentando cierta heterogeneidad con poblaciones de moléculas enzimáticas con contenido de oligosacáridos de 8 a 35 unidades de manosa. En su forma inmovilizada, exhibe una gran estabilidad frente a un amplio rango de valores de $\mathrm{pH}$ y temperatura. De esta forma, se ha implementado su uso en diferentes reacciones orgánicas, incluyendo muchas que han sido utilizadas a escala comercial (Kirk et al., 2002). Además, CALB se ha inmovilizado en muchos soportes hidrofóbicos con buenos resultados de rendimiento de inmovilización, estabilidad y recuperación de actividad enzimática (Fernández-Lorente et al., 2007).

\subsection{Mecanismo de acción de lipasas}

La información de las conformaciones estructurales de las lipasas permitió establecer que en su mecanismo catalítico ocurre un fenómeno denominado "activación interfacial de lipasas" (Desnuelle, 1972). El término es usado para describir el incremento en la actividad catalítica de este tipo de enzimas cuando interactúan con interfases hidrofóbicas (Verger, 1997; Reis, 2009; Palomo \& Guisan, 2012). La principal característica de las lipasas es la actividad en presencia de interfases hidrofóbicas (micelas de sustratos, solventes orgánicos no miscibles, etc.), descrita inicialmente por Sarda \& Desnuelle (1958). Posteriormente, se confirmaron los resultados previamente publicados con otros estudios cristalográficos (Brady et al., 1990; Brozozowski et al., 1991; Nobel et al., 1993; Ericsson et al., 2008).

De acuerdo con el mecanismo de activación interfacial, las lipasas muestran una cadena polipeptídica (lid) en su estructura secundaria, la cual cubre el sitio activo, impidiendo el acceso del sustrato (conformación cerrada) cuando se encuentran en ausencia de interfases. Sin embargo, en presencia de interfases hidrofóbicas, se presentan importantes cambios que dan lugar a la generación de una "conformación abierta" de la enzima en la cual el lid es desplazado como resultado de la exposición de superficies hidrofóbicas que ahora interactúan con la interfase. De esta manera, se confiere funcionalidad a la enzima (Palomo \& Guisan, 2012). Por otro lado, es evidente que las lipasas en medios acuosos presentan actividad catalítica, en muchos casos comparables a la de esterasas no lipásicas. Esto sugiere que las lipasas en sistemas acuosos homogéneos se encontrarían en un cierto equilibrio entre la conformación cerrada y la conformación abierta que les permiten ser catalíticamente activas en medios acuosos homogéneos.

\subsection{Modulación de las propiedades catalíticas de las lipasas}

La posibilidad de disponer de derivados enzimáticos altamente estables en condiciones de operación de la industria, es uno de los objetivos más importantes en reacciones de biotransformación. Para el caso particular de las lipasas, 
en las cuales se presenta un equilibrio conformacional, es interesante conocer cuál de las dos configuraciones es más estable. Es decir, la estructura abierta o la cerrada. De acuerdo con lo anterior, resulta interesante la preparación de diferentes derivados de lipasas en los cuales a través de estrategias de inmovilización sea posible la modulación de las propiedades catalíticas por la alteración del equilibrio conformacional existente (Bastida et al., 1998; Mateo et al., 2000, Barbosa et al., 2010).

El equilibrio conformacional de las lipasas sugiere que la permanencia de una estructura abierta o cerrada, se da a través de un gran número de fuerzas intra- e inter-moleculares. Por lo tanto, es posible que una variación en la densidad de carga de la enzima, altere la forma exacta del centro activo y en consecuencia las propiedades biocatalíticas de la lipasa. Para tal fin, es posible utilizar herramientas de ingeniería de proteínas tales como la modificación química de residuos aminoacídicos superficiales de la enzima, la ingeniería del medio de reacción y la ingeniería del derivado (Palomo \& Guisan, 2012; Marciello et al., 2012). En este trabajo se describirá la modificación química de la superficie de la enzima CALB en su forma inmovilizada y el efecto de las modificaciones sobre actividad, estabilidad y selectividad de la enzima.

\section{Metodología Experimental}

En este trabajo se llevaron a cabo diferentes estrategias de modificación química en la superficie enzimática de lipasa B de Candida antarctica inmovilizada en soportes de agarosa.

La primera modificación química ensayada fue la modificación de los ácidos carboxílicos expuestos de la enzima con etilendiamina (EDA) después de activación con carbodiimida (EDAC) (Carraway et al., 1969; Carraway \& Koshland, 1972) (Ver Figura 5). Esta modificación da la posibilidad de ionización de la superficie de la enzima pero produce a su vez una gran alteración de los grupos iónicos presentes en el superficie de la enzima. Esta modificación de proteína se ha usado para modular propiedades de lipasas (por ej. especificidad) (Palomo et al., 2007; Cabrera et al., 2009) y se ha usado para diversas aplicaciones como el mejoramiento de la inmovilización covalente multipuntual de enzimas (Fernández-Lorente et al., 2008; Rodrigues et al., 2009), o favoreciendo el entrecruzamiento intramolecular (Fernández-Lafuente et al., 1995). Esta modificación no es totalmente específica. La carbodiimida puede transformar algunos grupos carboxílicos en urea y modificar algunos residuos de Tyr. Sin embargo, esta última modificación química puede ser revertida por incubación de la proteína en presencia de hidroxilamina y obtener de esta manera Tyr en su forma libre no-modificada (Carraway \& Koshland, 1968).

La segunda modificación llevada a cabo en este trabajo fue la modificación de los grupos primarios de la superficie de la enzima con 2,3,4-trinitrobenceno-sulfonato (TNBS). Esta modificación de los grupos aminos primarios es altamente específica y se ha empleado para cuantificar grupos amino en proteínas y soportes (Snyder \& Sobocinski, 1975) (Ver Figura 6). Esta modificación producirá una hidrofobización de la superficie modificada dejando una amina secundaria con un grupo hidrofóbico anexado a éste. Este reactivo se ha usado para hidrofobizar soportes ante de la inmovilización de lipasas (Mendes et al., 2011). Debido a la alta especificidad de esta reacción, ésta se ha usado para elucidar la función estructural de los residuos de Lys en enzimas y proteínas (Jagtap \& Rao, 2006; Dash et al., 2001; Rao et al., 1996). Sin embargo, pocos estudios han considerado el efecto de este reactivo como una forma de modular las propiedades de enzimas. La modificación con TNBS se ha usado para aumentar la estabilidad de invertasa (Husain et al., 1996) y para aumentar la actividad maltosidasa de la enzima Alfaamilasa pancreática de cerdo (Yamashita et al., 1993). En este sentido, se propuso en este estudio llevar a cabo este tipo de

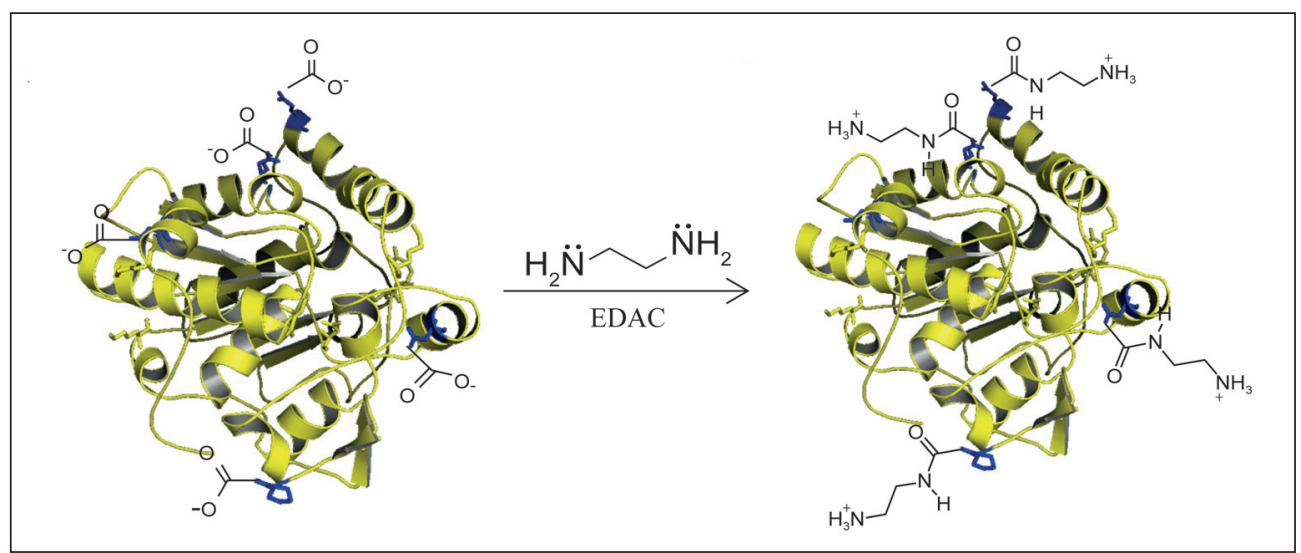

Figura 5. Aminación química de los grupos carboxilo de la superficie enzimática de CALB. Software de visualización Pymol 0.99. La estructura de la CALB fue tomada de Protein Data Bank (COD pdb 1TCA). 
modificaciones para posiblemente alterar la estructura de la forma abierta de la lipasa, producir cambios conformacionales en la estructura de la enzima o restringir el movimiento del lid, y de esta manera sus propiedades bioquímicas.

La tercera estrategia que se propuso en este trabajo fue la modificación química de CALB utilizando anhídrido succínico. En este caso, la densidad de carga superficial de CALB también puede ser alterada a través de la acilación de los grupos amino de lisinas con anhídrido succínico. De forma tal, que la modificación permite obtener derivados estables con mayor densidad de carga negativa (figura 7) a valores de $\mathrm{pH}$ donde los grupos carboxilo están desprotonados $(\mathrm{pH}$ mayor a 5). Además, puede llegar a alterar la solubilidad de la proteína al generar interacciones intermoleculares adicionales. Por lo tanto, es posible que la modificación de CALB parcial y totalmente con anhídrido succínico ocasione cambios estructurales en la conformación 3D de la enzima y en consecuencia una alteración de las propiedades biocatalíticas de la lipasa.
El control del grado de modificación se puede realizar a través de la cantidad de anhídrido succínico sólido adicionado a la reacción (Cabrera et al., 2009).

En general, se usaron diferentes estregias de inmovilización para CALB, las cuales eran compatibles con la modificación química de las enzimas.

La primera estrategia se llevó a cabo por adsorción hidrofóbica en soportes de octil-agarosa (Bastida et al., 1998), lo cual estabiliza la forma abierta de la lipasa, y pone el centro activo de la lipasa en un ambiente hidrofóbico, donde la concentración de los compuestos hidrofóbicos podría incrementarse por un efecto de partición (Fernández-Lorente $\boldsymbol{e t}$ al., 2007; Hernández \& Fernández-Lafuente, 2011).

La segunda estrategia fue inmovilización covalente de la enzima en dos diferentes tipos de soporte: (1) En soportes de agarosa activados con BrCN (March $\boldsymbol{e t}$ al., 1974). Con estos soportes, bajo condiciones de $\mathrm{pH}$ y tiempo adecuado,

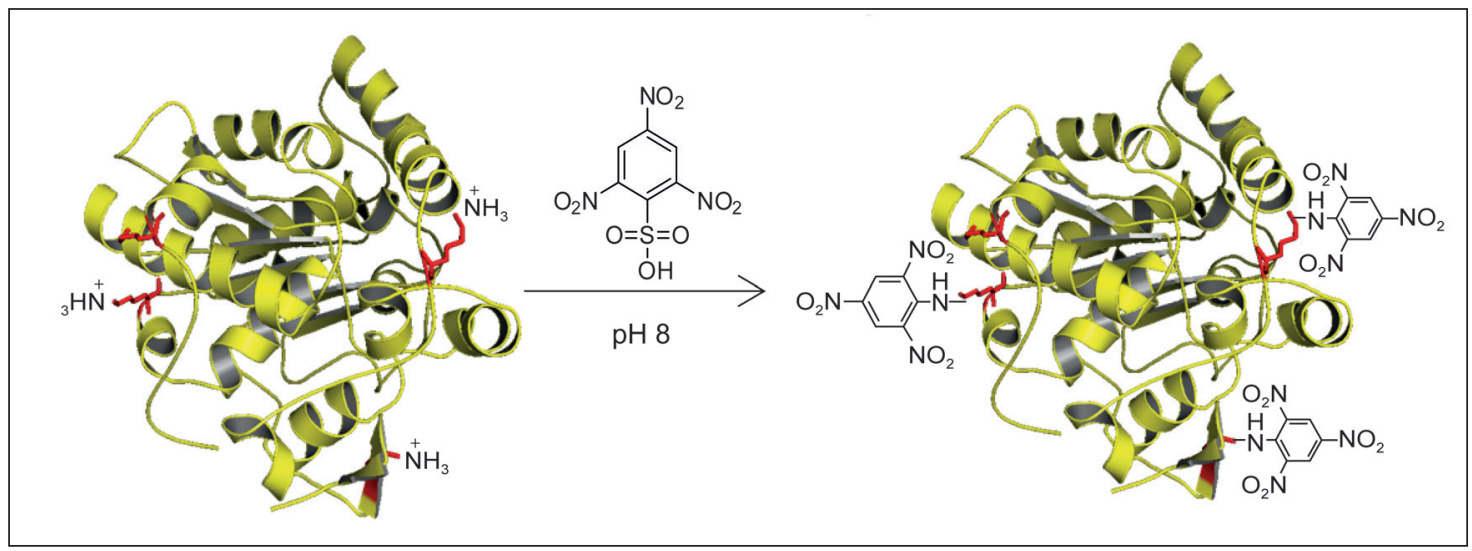

Figura 6. Modificación de los grupos amino primarios de la CALB con TNBS. Software de visualización Pymol 0.99. La estructura de la CALB fue tomada de Protein Data Bank (COD pdb 1TCA).

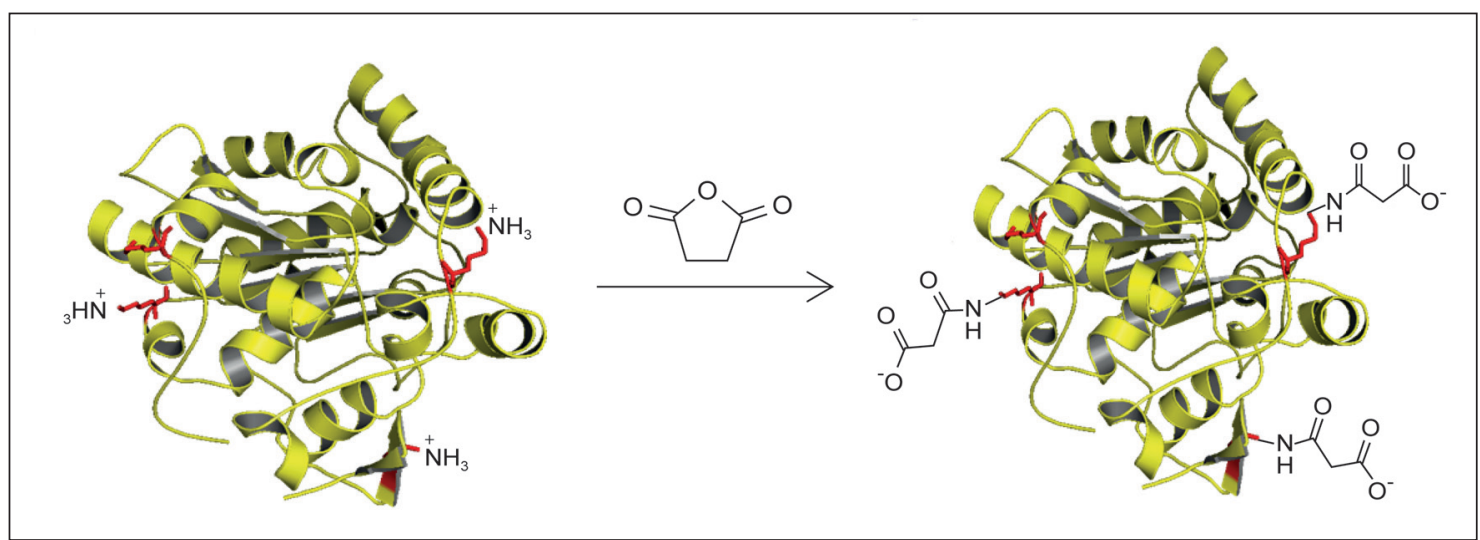

Figura 7. Succinilación química de la superficie enzimática de la CALB. Software de visualización Pymol 0.99. La estructura de la CALB fue tomada de Protein Data Bank (COD pdb 1TCA). 
se podría producir un enlace covalente multipuntual de la enzima sobre el soporte (Pedroche et al., 2007), que mantendría el equilibrio entre las formas abierta y cerrada de la lipasa. Además, a pH 7.0, se esperaría que la enzima llegara a ser inmovilizada sobre el sorporte por sus grupos amino, y muy probablemente por su amino-terminal (Mateo et al., 2005). Se ha descrito que esta forma inmovilizada de la lipasa spresenta a menudo diferentes propiedades en comparación con la enzima inmovilzada en octil-agarosa. (2) En soportes Eupergit C. En este caso la enzima se inmoviliza después de una adsorción de la enzima sobre el soporte (Mateo et al., 2007b). Esta enzima se inmovilizó previamente en este soporte en presencia del detergente triton X-100 para evitar adsorción interfacial de la enzima y alta fuerza iónica para forzar la adsorción de la enzima por otras regiones hidrofóbicas de la proteína (Barbosa et al., 2011).

2.1 Materiales. La lipasa B de Candida antarctica (CAL-B) fue obtenida de Novozymes. El Octil agarosa 4BCL, AgarosaBrCN, Tritón X-100, p-nitrofenilbutirato (pNPB), el ácido picril sulfónico (TNBS), 1-etil-3-(3-dimetilaminopropil) carbodiimida (EDAC), Etilendiamina (EDA), Anhídrido Succínico (AS), (R/S)-mandelato de metilo y cada uno de los isómeros puros fueron obtenidos de Sigma Aldrich (St. Louis, Mo, USA). El soporte de Eupergit $\mathrm{C}$ fue donado por Rohm Pharma (Darstamdt, Alemania). Los marcadores de peso molecular de proteínas para electroforesis de proteínas 1D y 2D se obtuvieron de Fermentas y Biorad, respectivamente. Los reactivos utilizados en la síntesis y en las reacciones fueron todos de grado analítico y suministrado por Sigma Aldrich y Merck.

2.2 Determinación de Actividad Enzimática. Se llevó a cabo por espectrofotometría, midiendo el incremento de la absorbancia a $348 \mathrm{~nm}$, producida por la liberación de p-nitrofenol durante la hidrólisis de $0.4 \mathrm{mM}$ del sustrato sintético p-nitro-fenil-butirato (p-NPB) disuelto en buffer fosfato $25 \mathrm{mM}$ (Quinn et al., 1982). Una Unidad Internacional de Actividad (U) se definió como la cantidad de enzima necesaria para hidrolizar 1 micromol de $\mathrm{p}$-NPB por minuto bajo las condiciones de ensayo $\left(\mathrm{pH} 7.0\right.$ y $\left.25^{\circ} \mathrm{C}\right)$.

2.3 Determinación de proteína. Se determinó usando el método de Bradford usando Albúmina de suero de bovino (BSA) como proteína estándar (Bradford, 1976).

2.4 Purificación de CALB. Para la purifiación de la enzima, la lipasa se inmovilizó en soportes de Octil-Agarosa (Bastida et al., 1998). En general, $1.6 \mathrm{~mL}$ de la enzima comercial se diluyó en $78.4 \mathrm{~mL}$ de una solución de fosfato de sodio $5 \mathrm{mM}$ a pH 7.0. Posteriormente se añadió a esta solución $8 \mathrm{~mL}$ de Octil-Agarosa y se mantuvo en agitación magnética durante $60 \mathrm{~min}$. Para evaluación de la actividad enzimática se tomaron periódicamente muestras de suspensión y sobrenadante. La enzima inmovilizada se lavó 3 veces con 80
$\mathrm{mL}$ de agua destilada. Para obtener la enzima soluble, se resuspendieron $8 \mathrm{~g}$ de Octil-Agarosa con CALB adsorbida en $80 \mathrm{~mL}$ de una solución $2 \%(\mathrm{v} / \mathrm{v})$ Triton X-100 disuelto en una solución $5 \mathrm{mM}$ sde fosfato de sodio phosphate a $\mathrm{pH} 7.0$ por $1 \mathrm{~h}$ a $25^{\circ} \mathrm{C}$, de manera de liberar la enzima del soporte.

\subsection{Electroforesis de Proteínas de CALB}

Se llevó a cabo utilizando geles de poliacrilamida (PAGE) en condiciones nativas y denaturalizantes (SDS-PAGE). Fueron llevadas a cabo de acuerdo con lo descrito por Laemmli, (1970). En general, las muestras de proteína soluble se disolvieron en Buffer Tris-HCl $62.5 \mathrm{mM}$ y pH 6.8, 2\% (p/v) SDS, $5 \%(\mathrm{v} / \mathrm{v})$ de beta-mercaptoetanol, 5\%(v/v) de glicerol. Estas muestras (20 microlitros) se hirvieron a ebullición por $5 \mathrm{~min}$. Los geles usados contenían poliacrilamida al $12 \%(\mathrm{p} / \mathrm{v})$ en el gel de separación y $5 \%(\mathrm{p} / \mathrm{v})$ en la zona de concentración. Para establecer la separación de las proteínas se usó una fuente de poder PowerPac HC (BIORAD) con un voltaje constante de $150 \mathrm{~V}$ a $25^{\circ} \mathrm{C}$ por $1 \mathrm{~h}$. Una vez finalizada la electroforesis, los geles se tiñeron con azul brillante de Coomassie R-250.

\subsection{Determinación de Punto Isoeléctrico (pI) de Proteínas de CALB}

Las muestras de enzimas (inmovilizadas o modificadas) se extrajeron y resuspendieron en 40 microlitros de buffer de lisis de prtoeínas (Urea, $7 \mathrm{M}$; tiourea, 2M; CHAPS, 4\%(p/v) y solución de anfolitos pH 3-10 al 1\% (v/v)) y solubilizaron por $1 \mathrm{~h}$ a temperatura ambiente bajo agitación magnética.

\subsubsection{Electroforesis Bi-Dimensional (2D) de proteínas de CALB}

Una muestra de proteína de $10 \mu \mathrm{g}$ se mezcló con buffer de rehidratación (urea, 7M; thiourea, 2M; CHAPS al 4\%(v/v); $0.5 \%(\mathrm{v} / \mathrm{v})$ de solución de anfolitos de $\mathrm{pH} 3-10$, DDT, 10 $\mathrm{mM}$; y DeStreak, $1.2 \%$ ) para obtener una volumen final de $200 \mathrm{~mL}$ y se aplicó a tiras de IPG de $11 \mathrm{~cm}, 3-10$ I (General Electric, Healthcare).

La primera dimensión se corrió a $0.075 \mathrm{~mA} /$ tira de $\mathrm{IPG}$ en el IPGforo IEF System (GE Healthcare) siguiendo un incremento de voltaje en 8 pasos: $30 \mathrm{~V} / \mathrm{h}$ por $8 \mathrm{~h}, 60 \mathrm{~V} / \mathrm{h}$ por $8 \mathrm{~h}$, $120 \mathrm{~V} / \mathrm{h}$ por $1 \mathrm{~h}, 250 \mathrm{~V} / \mathrm{h}$ por $1 \mathrm{~h}, 500 \mathrm{~V} / \mathrm{h}$ por $1 \mathrm{~h}, 1000 \mathrm{~V} / \mathrm{h}$ por $0: 30 \mathrm{~h}$, gradiente lineal a $8000 \mathrm{~V}$ en $0: 30 \mathrm{~h}, 8000 \mathrm{~V} / \mathrm{h}$ hasta que se alcanzara $12000 \mathrm{~V} / \mathrm{h}$. Después de la primera dimensión, las tiras se equilibraron por 10 min con Buffer de equilibración (Tris $50 \mathrm{mM}, \mathrm{pH} 8.8$; urea, 6M; Glicerol, 30\% (v/v); SDS, $2 \%(\mathrm{p} / \mathrm{v})$, trazas de azul de bromofenol) conteniendo DTT al $1 \%(\mathrm{p} / \mathrm{v}), \mathrm{y}$ después por $10 \mathrm{~min}$ adicionales usando buffer de equilibración conteniendo iodoacetamida al 4\%(p/v).

La segunda dimensión (SDS-PAGE) se llevó a cabo en geles de poliacrilamida al $12.5 \%(\mathrm{p} / \mathrm{v})(1 \mathrm{~mm}, 8 \mathrm{~cm} \times 7 \mathrm{~cm})$ usando una unidad de electroforesis Criterion Dodeca Cell (BIO RAD). $1.2 \mu 1$ de solución de proteínas estándar (Invitrogen) 
fueron pipeteados en $2 \mathrm{~mm}$ de papel filtro Whatman 3MM y puestos sobre el gel ceca de la zona ácida de cada tira de gel de isoelectroenfoque. Posteriormente los geles fueron corridos a Gels $20 \mathrm{~mA}$ por gel.

Una vez que la electroforesis finalizó, se tiñeron los geles con tinción de proteínas SYPRO Ruby (Invitrogen). Primero se fijó el gel en $\mathrm{MeOH}$ al $10 \%(\mathrm{v} / \mathrm{v})$ y ácido acético al 7\%(v/v) por $30 \mathrm{~min}$, se incubó en solución de tinción SYPRO Ruby toda la noche, y se lavó en una solución de metanol 10\%(v/v) y ácido acético 7\%(v/v) durante 30 minutos cada lavado, y finalmente dos lavados en agua destilada por 10 min cada lavado.

\subsubsection{Análisis de Imágenes de Geles}

Los geles teñidos con SYPRO Ruby fueron escaneados florímetro Typhoon TM 9400 en modo variable (General Electric, Healthcare) equipado con un láser de excitación a $532 \mathrm{~nm}$ (verde) y un filtro de emisión a $610 \mathrm{~nm}$ con un ancho de banda de $30 \mathrm{~nm}$ (SYPRO Ruby, ROX, EtBr) y $100 \mu \mathrm{m}$ de resolución. El setting del tubo fotomultiplicador fue fijado a $700 \mathrm{~V}$ para optimizar sensibilidad del equipo.

\subsection{Immovilización de CALB en soporte Eupergit C 250L}

La enzima CALB se desorbió de los soportes Octil-Agarosa usando Triton X-100 al 1\% (v/v) y a continuación se diluyó 10 veces. Posteriormente, se suspendió una masa de $10 \mathrm{~g}$ de soporte en $100 \mathrm{~mL}$ de solución enzimática (conteniendo 32 $\mu \mathrm{g} / \mathrm{mL}$ de proteína en una solución de fosfato de sodio $1 \mathrm{M}$ con $0.1 \%(\mathrm{v} / \mathrm{v})$ de Triton X-100 a pH 7) a $25^{\circ} \mathrm{C}$ por $48 \mathrm{~h}$ (Barbosa et al., 2011; Barbosa et al., 2010). Periódicamente, se sacaron muestras de sobrenadante y suspensión y se midió actividad enzimática tal como se describió previamente. A continuación, y para bloquear los grupos epóxidos, la preparación inmovilizada de la enzima se incubó en $50 \mathrm{~mL}$ de fosfato de sodio $50 \mathrm{mM}$ conteniendo $5 \%(\mathrm{v} / \mathrm{v})$ de mercaptoetanol a pH 8 y $25^{\circ} \mathrm{C}$ por $24 \mathrm{~h}$ (Mateo et al., 2007a, b; Barbosa et al., 2011; Barbosa et al., 2010). Finalmente, la preparación inmovilizada de CALB se lavó con agua destilada y se almacenó a $4{ }^{\circ} \mathrm{C}$.

\subsection{Immovilización de CALB en soporte octil-agarosa}

La lipasa se inmovilizó en octil-agarosa a baja fuerza iónica (Bastida et al., 1998). Se diluyeron $2 \mathrm{~mL}$ de CALB comercial (actividad específica de $21 \mathrm{U} / \mathrm{mg}$ proteína) en $98 \mathrm{~mL}$ de una solución de fosfato de sodio $5 \mathrm{mM}$ ajustada a $\mathrm{pH} 7$. En algunos casos, se agregó etanol en diferentes cantidades porcentuales $(\mathrm{v} / \mathrm{v})$. A continuación, se añadió a esta solución una masa de $20 \mathrm{~g}$ de octil agarosa. Esta susensión se dejó por una $1 \mathrm{~h}$ y $25^{\circ} \mathrm{C}$ bajo agitación a $250 \mathrm{rpm}$. En algunos casos, se inmovilizó durante $3 \mathrm{~h}$ a $4^{\circ} \mathrm{C}$. La suspensión enzimática una vez inmovilizada, se filtró y la lipasa soportada en el gel de agarosa se lavó varias veces con agua destilada.

\subsection{Immovilización de CALB en soporte de BrCN-agarosa}

Este soporte se usó para chequear el efecto de la modificación con glutaraldehído y se llevó a cabo siguiendo un protocolo previamente establecido para esta enzima (Barbosa et al., 2012). Un volumen de $1 \mathrm{ml}$ de CALB comercial se diluyó en $99 \mathrm{ml}$ de una solución de fosfato de sodio $5 \mathrm{mM}$ a pH 7. Posteriormente, se añadió $6 \mathrm{~g}$ de soporte $\mathrm{BrCN}$-agarosa a la solución enzimática. Después de transcirridos 90 min a $4{ }^{\circ} \mathrm{C}$ bajo agitación a $250 \mathrm{rpm}$, se inmoilivzó alrededor de un $45 \%$ de la lipasa sobre el soporte. La inmovilización enzimática sobre el soporte finalizó por incubación de la enzima inmovilizada en el soporte con una solución $1 \mathrm{M}$ de etanolamina a pH 8 por $2 \mathrm{~h}$. Finalmente, se lavó la preparación inmovilizada con agua destilada.

\subsection{Aminación de CALB inmovilizada}

Se añadieron $100 \mathrm{~mL}$ de EDA $1 \mathrm{M}$ a $10 \mathrm{~g}$ de CALB o CALBTNBS inmovilizada a pH 4.75 bajo agitación continua. La modificación comenzó con la adición de EDAC sólida para obtener una concentración final de $10 \mathrm{mM}$ en una sóla adición. Después de 90 min de agitación suave a $25^{\circ} \mathrm{C}$, loa derivados aminados (denominados CALB-EDA y CALB-TNBS-EDA) tenían modificados un $100 \%$ de los grupos carboxílicos expuestos en su superficie enzimática (Fernández-Lafuente et al., 1995; Rodrigues et al., 2011). Finalmente, la enzima inmovilizada y modificada se lavó con un exceso de agua destilada y almacenó a $4^{\circ} \mathrm{C}$.

\subsection{Modificación de los grupos amino de CALB con TNBS}

Se añadieron $12 \mathrm{~g}$ de CALB o CALB-TNBS a $100 \mathrm{ml}$ de una solución de TNBS al $0.1 \%(\mathrm{p} / \mathrm{v})$ en una solución de fosfato de sodio $25 \mathrm{mM}$ a pH 8.0 y la mezcla se incubó durante $60 \mathrm{~min}$ a temperatura ambiente. Posteriormente, se lavó la preparación de la enzima modificada con agua destilada (Snyder et al., 1975). Las preparaciones se llamaron CALB-TNBS o CALB-TNBS-EDA-TNBS.

\subsection{Modificación de CALB con Anhídrido Succínico}

Se añadió $1 \mathrm{~g}$ de derivado CALB inmovilizada en Octilagarosa se incubó en $10 \mathrm{~mL}$ de buffer fosfato $10 \mathrm{mM}$ de $\mathrm{pH} 8$ bajo agitación magnética continua a temperatura ambiente. La reacción de modificación se inició con la adición de anhídrido succínico en diferentes concentraciones: 1,20 y $100 \mathrm{mM}$, para obtener modificaciones de 10,50 y $100 \%$, respectivamente. Después de 120 minutos de agitación, los derivados de la CALB succinilada (CALB-S), se lavaron con buffer fosfato pH 7 y un exceso de agua destilada. Posteriormente, se filtraron al vacío, y se almacenaron a $4^{\circ} \mathrm{C}$ (Cabrera et al., 2009). Los derivados obtenidos se llamaron OC-CALB-S- $10 \%$, OCCALB-S-50\% y OC-CALB-S-100\%. Las condiciones de modificación anteriormente descritas fueron aplicadas también en el derivado de CALB inmovilizado en Eupergit C. 


\subsection{Desorción de CALB adsorbida sobre octil-agarosa}

Se incubó la enzima inmovilizada en octil-agarosa en presencia de concentraciones crecientes de Tritón X-100 y determinó su actividad enzimática en el sobrenadante y la suspensión enzimática. Una vez que se añadió el detergente, se dejaron por 30 min antes de retirar las muestras de sobrenadante y suspensión para su análisis de actividad. Para cuantificar el efecto del detergente sobre la actividad de la enzima, se sometió una muestra de CALB soluble a las mismas condiciones.

\subsection{Inactivación térmica de diferentes preparaciones de CALB}

Para llevar a cabo estas inactivaciones, se tomaron $100 \mathrm{mg}$ of diferentes preparaciones de CALB (solubles, inovlizadas y/o modificadas) y se incubaron en buffer fosato $25 \mathrm{mM}$, $\mathrm{pH} 7 \mathrm{y}$ a diferentes temperaturas, dependiendo del experimento. Se tomaron muestras a diferentes tiempos de las preparaciones de CALB incubadas y se midió su actividad enzimática residual usando el método de p-NPB descrito previamente.

Para chequear la estabilidad de las preparaciones enzimáticas, $1 \mathrm{~mL}$ de enzima inmovilizada se suspendió en $10 \mathrm{~mL}$ de una solución de acetato de sodio $25 \mathrm{mM}$ a pH 5 , fosfato de sofio $25 \mathrm{mM}$ a pH 7 y borato de sodio $25 \mathrm{mM}$ a pH 9 a diferentes temperaturas. Periódicamente, se sacaron muestras de preparaciones enzimáticas y se midió su actividad residual usando pNPB como sustrato.

\subsection{Ensayos de estabilidad enzimática en presencia de solventes orgáinicos}

Se incubaron las diferentes preparaciones enzimátias (soluble, inmovilizadas o modificadas) en mezclas de co-solvente orgánico/buffer Tris-HCl $50 \mathrm{mM}$ a pH 7 y diferentes temperaturas. La presencia de una muy pequeña cantidad de cosolvente orgánico $(50 \mu \mathrm{l})$ durante los ensayos de actividad enzimática hidrolítica, no afectó las velocidades de reacción enzimática observadas.

\subsection{Hidrólisis de R y S mandelato de metilo}

La actividad enzimática se determinó también usando R o $\mathrm{S}$ mandelato de metilo. Se añadieron $50 \mathrm{mg}$ de las preparaciones inmovilizadas a $3 \mathrm{~mL}$ solución de mandelato de metilo $10 \mathrm{mM}$ disuelta en buffer fosfato $25 \mathrm{mM}$ a pH 7.0 y somerido a agitación continua. El grado de conversión se analizó por RP-HPLC (Agilent 1100) usando una columna Zorbax C-18 $(5 \mu \mathrm{m}, 250 \mathrm{~mm} \times 4.6 \mathrm{~mm})$. Se inyectaron muestras de $5 \mu \mathrm{l}$ al equipo y se eluyeron con un flujo de $1.0 \mathrm{~mL} / \mathrm{min}$ usando Acetonitrilo/Buffer fosfato de amonio $25 \mathrm{mM}(35: 65, \mathrm{v} / \mathrm{v})$ como fase móvil. La detección de los compuestos hidrolizados se llevó a cabo usando un detector de arreglos de diodos con detección UV a $225 \mathrm{~nm}$. Una unidad de actividad enzimática se definió como la cantidad de enzima necesaria para producir $1 \mu \mathrm{mol}$ de ácido mandélico bajo las condiciones descritas previamente. La actividad se determinó por triplicado con una conversión máxima de $20-30 \%$, y los datos son dados como valores promedios. La enantioespecificidad (E) se calculó directamente a partir de las razones de las velocidades de reacción con el isómero $\mathrm{R}$ y S (Chen et al., 1982).

\section{Resultados y Discusión}

\subsection{Modificación Química de Biocatalizadores de CALB con EDA y TNBS}

En la Figura 9 se muestran los diferentes grupos que pueden ser modificados utilizando EDA y TNBS en la proximidad del lid y del centro activo de la enzima. Entre ellos, es importante señalar el Asp-145 que hace parte del lid (GLY-PRO-LEU-ASP-ALA), y se encuentra a menos de $10 \AA$ del residuo de Glu-294. Este último grupo está muy cerca de la Lys-308 y Arg-309. Por tanto, las modificaciones químicas utilizadas en este trabajo podrían alterar las interacciones químicas en la zona próxima al centro activo, quizás alterando el movimiento del lid y de esta manera las propiedades bioquímicas de la lipasa. En un área diferente de la proteína, el Asp-187, el Asp-223 y el Glu-188 se encuentran también muy cerca de la región del lid, por lo que la modificación puede afectar los movimientos del lid de igual forma.

La inmovilización reversible de CALB sobre OC evita probables pérdidas de actividad por las condiciones de reacción de cada modificación química; permite desorber del soporte las moléculas de enzima modificadas utilizando un detergente; y permite la caracterización de las mismas mediante técnicas convencionales.

La Figura 10 presenta la electroforesis nativa de los diferentes derivados modificados de CALB. Se aprecia que solo fue posible visualizar los derivados OC-CALB y OC-CALBTNBS. Teniendo en cuenta que en este tipo de electroforesis, las proteínas migran en razón a su relación carga/masa, es posible que la modificación con EDA de los derivados de OC-CALB haya alterado el punto isoeléctrico de la enzima por encima del $\mathrm{pH}$ del buffer de corrida $(\mathrm{pH} 8)$ y por lo tanto no aparezcan en el gel. Este comportamiento era esperado, debido a que la modificación de CALB con EDA incrementa la densidad de cargas positivas sobre la superficie de la enzima, lo cual a su vez ocasiona un decrecimiento drástico de los grupos aniónicos externos de la lipasa (FernándezLafuente et al., 1998; Rodrigues et al., 2011).

Los resultados de la electroforesis nativa fueron confirmados determinando los puntos isoeléctricos (pI) de las 5 preparaciones a través de una electroforesis en 2D (Ver Tabla 1). Los resultados obtenidos muestran que la modificación de CALB con TNBS (CALB-TNBS) no afectó el punto 


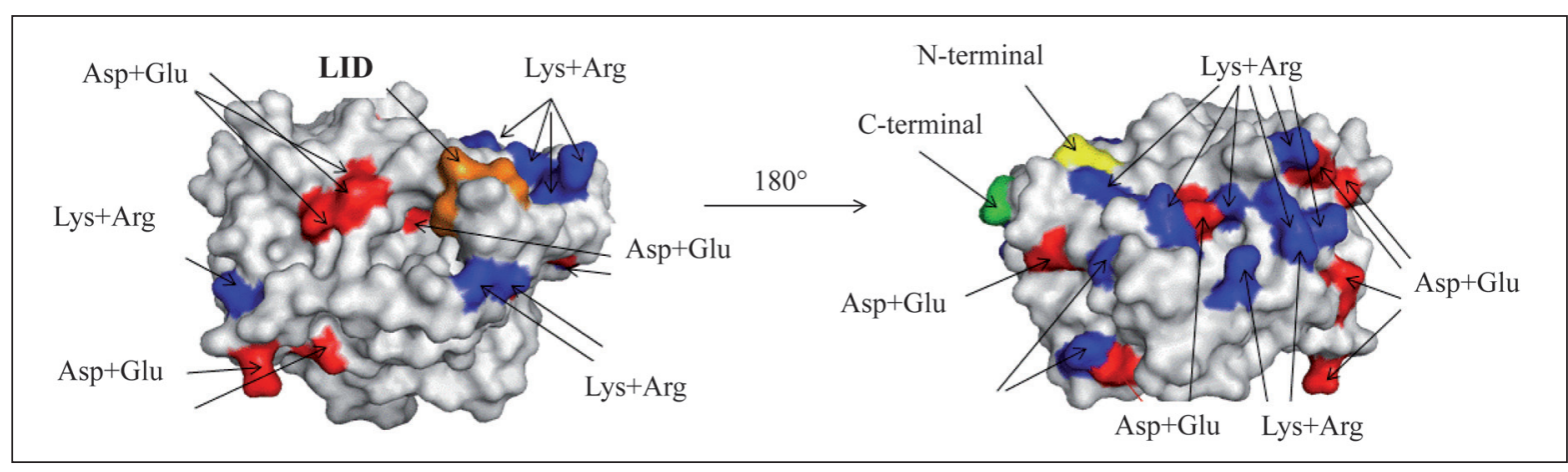

Figura 9. Modelo de estructura 3D de la superficie de CALB indicando los residuos lisínicos, los ácidos carboxílicos y las argininas. La estructura de superficie 3D fue modelada usando el visualizador Pymol 0.99. La estructura 3D de CALB fue obtenida de Protein Data bank (PDB), código 1TCA.

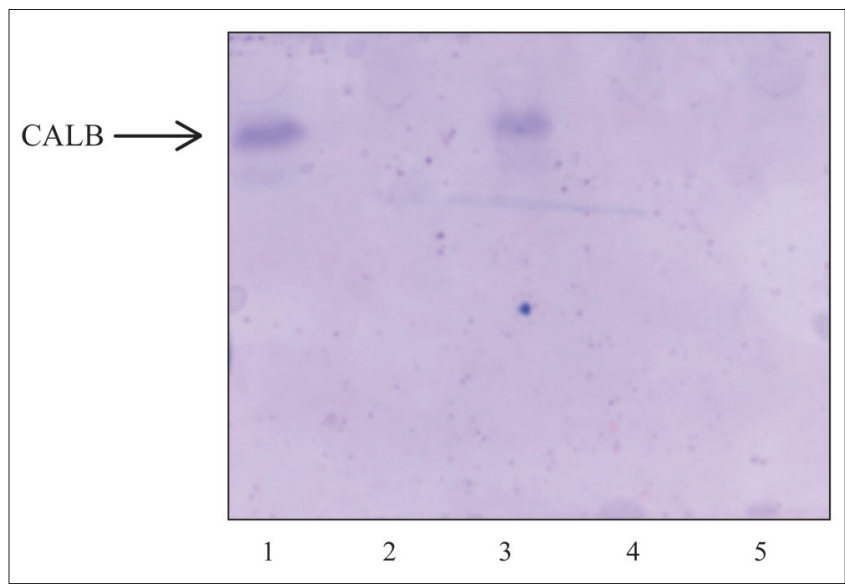

Figura 10. Electroforesis nativa de los diferentes derivados modificados de CALB. Carril 1: CALB; carril 2: CALB-EDA; carril 3: CALB-TNBS; carril 4: CALB-TNBS-EDA; carril 5: CALBTNBS-EDA-TNBS.

isoeléctrico de la enzima ( $\mathrm{pI}=5.8-5.9)$, mientras que la modificación con EDA(CALB-EDA), ocasionó un cambio notable en el punto isoeléctrico de la CALB (pI>11).

Por su parte, los derivados CALB-TNBS-EDA y CALBTNBS-EDA-TNBS alcanzaron un punto isoeléctrico mayor que la enzima no modificada. Los resultados obtenidos se deben probablemente a la formación de aminas secundarias con un valor de pKa más bajo que los pKa de las lisinas y de los nuevos grupos amino introducidos (FernandezLafuente et al., 1998).

La Tabla 2 muestra los cambios en la actividad frente al p-NPB (a pH 7) de los derivados OC-CALB y BrCN-CALB producidos por la modificación química secuencial con EDA y TNBS. Los resultados son diferentes dependiendo de la preparación de CALB inmovilizada y del agente modificante empleado. La aminación del derivado OC-CALB produjo un
Tabla 1. Puntos isoeléctricos de las diferentes preparaciones modificadas de CALB. Los experimentos se realizaron de acuerdo con lo descrito en la sección de materiales y métodos.

\begin{tabular}{lc}
\hline Derivado & Punto Isoeléctrico $(\mathbf{p I})$ \\
\hline CALB & $5.8-5.9$ \\
CALB-TNBS & $5.8-5.9$ \\
CALB-EDA & $>11^{*}$ \\
CALB-TNBS-EDA & $8.8-8.9$ \\
CALB-TNBS-EDA-TNBS & $8.6-8.7$ \\
\hline
\end{tabular}

* Los geles utilizados permitían identificar el pI en el intervalo de pH 4-pH 11.

incremento en la actividad frente al p-NPB de $40 \%$, mientras que la modificación con TNBS del mismo derivado produjo una disminución del $20 \%$ en la actividad frente p-NPB.

Usando el derivado BrCN-CALB, la modificación química con EDA y con TNBS produjo una disminución dramática en la actividad enzimática frente al p-NPB, siendo más significativo el efecto adverso cuando se usó EDA (la actividad disminuyó alrededor del 50\%) que cuando se utilizó TNBS (la actividad disminuyó 40\%).

Las diferencias generadas por la modificación química con EDA o TNBS, según sea el derivado de CALB usado, pueden deberse a varias causas. Por ejemplo, es posible que algunos grupos de CALB ubicados en un ambiente altamente hidrofóbico e implicados en la adsorción de la enzima al soporte OC (como el Asp-145, que se encuentra en el lid) no hayan sido modificados por el agente hidrofílico (EDA), permitiendo una mayor recuperación de la actividad enzimática (Hernández \& Fernández-Lafuente, 2011; Hernández et al., 2011). Otra posibilidad, es que mientras la lipasa adsorbida sobre el soporte Octil-Agarosa desplace y fije el lid, estabilizando la conformación abierta, la CALB inmovilizada de manera covalente tiene el lid completamente libre para moverse. Aunque el centro activo de CALB inmovilizado en $\mathrm{BrCN}$ no 
esté completamente aislado del medio, es probable que después de la modificación química, algunos movimientos del lid se encuentren restringidos por impedimentos estéricos de manera que el efecto final de la modificación es una disminución en la actividad enzimática.

La posterior modificación con EDA de los derivados $\mathrm{OC}$ CALB-TNBS y BrCN-CALB-TNBS altera el balance de cargas sobre la superficie enzimática al cambiar grupos aniónicos (grupos carboxilos ionizados) por grupos catiónicos (grupos amino ionizados), ocasionando probablemente un cambio conformacional en la enzima. En este sentido, la aminación del derivado OC-CALB-TNBS incrementó la actividad enzimática del nuevo derivado OC-CALB-TNBS-EDA en la hidrólisis del pNPB en un 15\% y 30\% en comparación con los derivados OC-CALB y OC-CALB-TNBS, respectivamente.

El efecto final de la modificación con EDA fue diferente cuando se utilizó el derivado BrCN-CALB-TNBS. La actividad del nuevo derivado BrCN-CALB-TNBS-EDA frente al pNPB disminuyó $41 \%$ y $5 \%$ con relación a los derivados $\mathrm{BrCN}$ CALB y BrCN-CALB-TNBS, respectivamente (Ver Tabla 2). La disminución en la actividad de los derivados de CALB inmovilizados de forma covalente con EDA se debieron posiblemente a que la modificación pudo haber cambiado algunas interacciones electrostáticas existentes entre el lid y el área del centro activo de la proteína, por fuerzas de repulsión. Por ejemplo, es posible que la aminación de los residuos Asp145 y Glu-294, o la modificación con TNBS del residuo de Lys-308 haya ocasionado algún efecto sobre el movimiento del lid.

Los derivados OC-CALB-TNBS-EDA y BrCN-CALB-TNBSEDA fueron modificados con TNBS. La modificación puede ocasionar un incremento en la hidrofobicidad de la enzima, ya que implica la introducción de 15 grupos trinitrobencil más (25 grupos TNBS en total) sobre la superficie de CALB. Los resultados obtenidos señalan que el derivado OC-CALBTNBS-EDA-TNBS fue 30\% y $60 \%$ menos activo en la hidrólisis de pNPB que los derivados OC-CALB y OC-CALBTNBS-EDA, respectivamente. Por su parte, la modificación

Tabla 2. Actividad relativa de los diferentes derivados de CALB modificados con TNBS y EDA en la hidrólisis de pNPB (0.4 mM) a pH 7 y $\mathbf{2 5}^{\circ} \mathbf{C}$. $100 \%$ corresponde a la actividad relativa del derivado de CALB no modificado. Los experimentos se realizaron de acuerdo con lo descrito en la sección métodos analíticos.

\begin{tabular}{lccccc}
\hline & \multicolumn{5}{c}{ Actividad relativa } \\
\cline { 2 - 6 } Derivado & CALB & $\begin{array}{c}\text { CALB- } \\
\text { EDA }\end{array}$ & $\begin{array}{c}\text { CALB- } \\
\text { TNBS }\end{array}$ & $\begin{array}{c}\text { CALB- } \\
\text { TNBS-EDA }\end{array}$ & $\begin{array}{c}\text { CALB-TNBS- } \\
\text { EDA-TNBS }\end{array}$ \\
\hline OC & 100 & $140 \pm 3$ & $83 \pm 4$ & $115 \pm 5$ & $70 \pm 2$ \\
BrCN & 100 & $49 \pm 2$ & $63 \pm 3$ & $59 \pm 2$ & $58 \pm 1$ \\
\hline
\end{tabular}

del derivado de CALB inmovilizado de manera covalente BrCN-CALB-TNBS-EDA no afectó de forma significativa la actividad enzimática frente a pNPB del nuevo derivado.

Las diferencias de actividad encontradas entre los derivados OC-CALB-TNBS-EDA-TNBS y BrCN-CALB-TNBS-EDATNBS se deben posiblemente a que mientras en el derivado inmovilizado por adsorción interfacial la modificación con TNBS ocasionó cambios en las interacciones existentes entre los residuos Asp-167, Glu-223 y Glu-188 alterando desfavorablemente la forma del centro activo, en el derivado inmovilizado covalentemente es probable que la modificación no haya tocado los residuos anteriormente mencionados.

Considerando que los derivados de OC-CALB modificados con TNBS y EDA retuvieron el mayor porcentaje de su actividad enzimática, y además, exhibieron una mayor estabilidad en comparación con los derivados modificados de BrCN-CALB, los estudios que se describen a continuación se realizaron solo con los derivados de OC-CALB.

La Figura 11 muestra el efecto del pH sobre la actividad de los 5 derivados de OC-CALB modificados con EDA y TNBS. Sobresalen las diferencias en el valor del pH óptimo entre el derivado OC-CALB-EDA que exhibió la máxima actividad a $\mathrm{pH} 7$ y el derivado no modificado OC-CALB que presentó la máxima actividad a pH 9.

El derivado OC-CALB-EDA presentó mayor actividad en todo el rango de $\mathrm{pH}$ estudiado (rango de $\mathrm{pH}$ 5-10) en comparación con el derivado no modificado. El derivado OCCALB-EDA, presentó un marcado efecto de hiperactivación, con respecto al derivado no modificado a valores de $\mathrm{pH}$ entre pH 5 y pH 7. Por ejemplo, a pH 5 y pH 6, la actividad de OCCALB-EDA se incrementó $180 \%$ y $170 \%$ en comparación con la actividad del derivado OC-CALB frente al pNPB (Ver Figura 9). Sin embargo, a pH 10, donde la enzima no modificada disminuyó su actividad un $65 \%$, el derivado OCCALB-EDA retuvo el $44 \%$ de la actividad máxima exhibida a $\mathrm{pH} 7$.

El derivado OC-CALB-TNBS-EDA, a pH 5, incrementó en un $60 \%$ la actividad enzimática en comparación con la enzima no modificada. En el rango de $\mathrm{pH}$ entre $\mathrm{pH} 7$ y $\mathrm{pH} 9$ este incremento estuvo entre el $10 \%$ y $15 \%$ en comparación con OC-CALB, y entre 30\% y 40\% cuando se comparó con el derivado OC-CALB-TNBS. A pH 10, el derivado OC-CALBTNBS-EDA fue menos activo que OC-CALB-EDA y OCCALB, reteniendo tan solo el $20 \%$ de su actividad máxima.

El incremento en la actividad enzimática de los derivados $\mathrm{OC}$ CALB-EDA y OC-CALB-TNBS-EDA frente a la hidrólisis de $\mathrm{pNPB}$ en el rango de $\mathrm{pH} 5$ a pH 8 en comparación con el derivado no modificado OC-CALB, se debió posiblemente a que el tratamiento con EDA generó una conformación estructural de la enzima más favorable al modificar los 


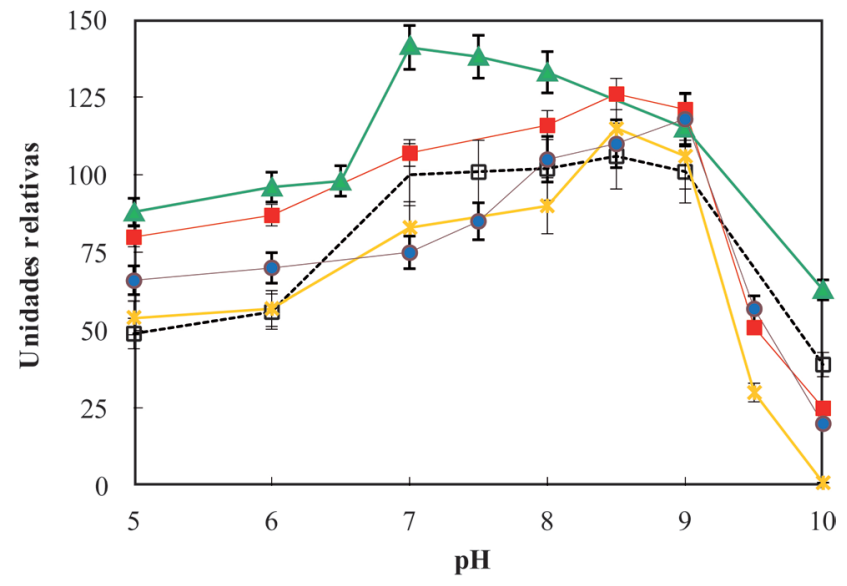

Figura 11. Influencia del valor del pH sobre la actividad de los diferentes derivados modificados de OC-CALB. Los experimentos se realizaron a $25{ }^{\circ} \mathrm{C}$, usando p-NPB $0.4 \mathrm{mM}$ como sustrato, de acuerdo con lo descrito en la sección de materiales y métodos. 100 unidades relativas corresponden a la actividad del derivado no modificado OC-CALB a pH 7. ( $\square$ ) OC-CALB ( $\Delta$ ) OC-CALB-EDA; (x) OC-CALB-TNBS (ロ) OC-CALB-TNBS-EDA; (•) OC-CALBTNBS-EDA-TNBS.

residuos Asp-187, Asp-223 y el Glu-188 (Ver Figura 9) que se encuentran muy cerca de la región del lid, afectando los movimientos del mismo y cambiando la forma exacta del centro activo. Sin embargo, a valores de $\mathrm{pH} 9$ y 10 , es posible que la actividad haya disminuido en comparación con OC-CALB debido a que los nuevos grupos amino introducidos sobre la superficie enzimática se encuentran desprotonados -tienen un valor de pK de 9.2- ocasionando la pérdida de interacciones electrostáticas que mantenían una conformación más activa (Rodrigues et al., 2009; Cabrera et al., 2009; Diaz-Rodriguez \& Davis, 2011).

El derivado OC-CALB-TNBS presentó una actividad muy similar al derivado no modificado OC-CALB en el rango de valores de $\mathrm{pH}$ estudiados (rango de $\mathrm{pH}$ 5-7). Las diferencias más notables se encontraron a $\mathrm{pH} 7$, en donde el derivado OC-CALB-TNBS disminuyó la actividad enzimática un $20 \%$ frente al pNPB, con respecto al derivado OC-CALB. A pH 10, el derivado OC-CALB retiene cerca del $30 \%$ de su actividad mientras que OC-CALB-TNBS se inactivó por completo.

Finalmente, el derivado OC-CALB-TNBS-EDA-TNBS fue entre $20 \%$ y $30 \%$ menos activo que el derivado OCCALB-TNBS-EDA, en todo el rango de $\mathrm{pH}$ estudiado. Estos resultados reafirman que la modificación con TNBS causó un efecto negativo sobre la actividad de CALB, debido probablemente a que con la introducción de los grupos trinitrobencil se rompieron interacciones electrostáticas importantes para el mantenimiento de una conformación de la enzima más activa.
La Tabla 3 muestra los tiempos de vida media de los derivados de OC-CALB modificados con TNBS y EDA, bajo diferentes condiciones de inactivación térmicas. Éstas fueron realizadas sobre el derivado OC-CALB a pH 5, pH 7 y $\mathrm{pH} 9$, mostraron que la enzima no modificada es altamente estable a $\mathrm{pH} 5$, mientras que a $\mathrm{pH} 9$ su tiempo de vida media fue corto, incluso a una temperatura más baja $\left(50{ }^{\circ} \mathrm{C}\right.$ a pH 9 y $60^{\circ} \mathrm{C}$ a pH 5 y pH 7).

La modificación con EDA produjo una disminución en la estabilidad de CALB en los valores estudiados de $\mathrm{pH} 5$, 7 y 9. A pH 7, la estabilidad decreció en un factor de 5 en comparación con el derivado OC-CALB, mientras que a valores de $\mathrm{pH} 5$ y 9 disminuyeron en un factor de 1.35 y 1.4, respectivamente.

La modificación con TNBS redujo la estabilidad del derivado OC-CALB a pH 5 en un factor de 2 y a pH 7 en un factor de 1.6. Sin embargo, a pH 9 esta modificación incrementó la estabilidad de OC-CALB por un factor de 1.4. Comparando la estabilidad del derivado modificado con EDA(OC-CALBEDA) con el derivado OC-CALB-TNBS, la modificación química únicamente con TNBS produjo derivados menos estables a pH 5.

El derivado OC-CALB-TNBS-EDA fue menos estable que el derivado OC-CALB-TNBS a $\mathrm{pH} 7$ y $\mathrm{pH} 9$, en un $28 \%$ y $52 \%$, respectivamente. Sin embargo, a pH 5, el derivado OCCALB-TNBS-EDA fue $28 \%$ más estable que OC-CALB. Por su parte, el derivado OC-CALB-TNBS-EDA-TNBS fue el biocatalizador menos estable bajo las condiciones estudiadas. Esto sugiere que el aumento en la hidrofobicidad de la superficie de CALB ocasionada por la modificación con TNBS, produce un efecto desestabilizante sobre la enzima debido probablemente a que con la introducción de los grupos trinitrobencil se rompieron interacciones electrostáticas que contribuían en la estabilidad de la estructura 3D de la enzima (Ueji et al., 2003; Rodrigues et al., 2011).

La estabilidad de los derivados OC-CALB, OC-CALB-EDA, OC-CALB-TNBS, OC-CALB-TNBS-EDA y OC-CALBTNBS-EDA-TNBS fue evaluada de forma similar a $37^{\circ} \mathrm{C}$. En este caso, todos los derivados de OC-CALB modificados mantuvieron cerca del $95 \%$ de sus actividades después de una semana de incubación.

La estabilidad de los derivados modificados de CALB fue evaluada en presencia de una mezcla de $50 \%(\mathrm{v} / \mathrm{v})$ de dioxano/ buffer Tris- $\mathrm{HCl} 100 \mathrm{mM}$ a valores de $\mathrm{pH} 5,7$ y 9 a $60^{\circ} \mathrm{C}$, de acuerdo con lo descrito en la sección de métodos experimentales.

Los resultados presentados en la Tabla 3 demuestran que las modificaciones químicas produjeron un decrecimiento en la estabilidad de los diferentes derivados de CALB modificados con EDA y TNBS. En general, los tiempos de vida media de 
Tabla 3. Tiempos de vida media (horas) de los diferentes derivados modificados de OC-CALB en presencia de Dioxano $50 \%(\mathrm{v} / \mathrm{v})$ a diferentes valores de pH. Los experimentos se realizaron de acuerdo con lo descrito en la sección de métodos experimentales.

\begin{tabular}{|c|c|c|c|}
\hline \multirow{2}{*}{ DERIVADO } & \multicolumn{3}{|c|}{ Tiempo de Vida Media (h) } \\
\hline & pH $5,45^{\circ} \mathrm{C}$ & $\mathrm{pH} 7, \mathbf{4 5}^{\circ} \mathrm{C}$ & pH 9, $45^{\circ} \mathrm{C}$ \\
\hline OC-CALB & $2 \pm 0.15$ & $4.8 \pm 0.15$ & $1.8 \pm 0.12$ \\
\hline OC-CALB-EDA & $1.5 \pm 0.05$ & $3.5 \pm 0.15$ & $1 \pm 0.07$ \\
\hline OC-CALB-TNBS & $1.8 \pm 0.1$ & $5.5 \pm 0.25$ & $1 \pm 0.05$ \\
\hline OC-CALB-TNBS-EDA & $0.9 \pm 0.1$ & $2.8 \pm 0.1$ & $3 \pm 0.15$ \\
\hline OC-CALB-TNBS-EDA-TNBS & $1.5 \pm 0.1$ & $2.5 \pm 0.15$ & $2.5 \pm 0.15$ \\
\hline
\end{tabular}

estos derivados se redujeron (sin exceder en un factor de 2) en comparación con el derivado no modificado OC-CALB. Las excepciones fueron el derivado OC-CALB-TNBS que fue 1.5 veces más estable a $\mathrm{pH} 7$ y el derivado OC-CALBTNBS-EDA que fue 1.6 veces más estable a pH 9.

De nuevo, el punto más relevante es que a pesar de las múltiples modificaciones químicas realizadas sobre la superficie de CALB, los derivados obtenidos retuvieron niveles aceptables (superiores a 50\%) de estabilidad en presencia de dioxano. Los derivados de OC-CALB modificados con EDA y TNBS, fueron incubados a valores de $\mathrm{pH} 5,7$ y 9 a $25^{\circ} \mathrm{C}$ por una semana. Las actividades residuales de todas las preparaciones fueron superiores al $90 \%$, destacando la elevada estabilidad a temperatura ambiente de los derivados de OC-CALB modificados.

Es posible que los efectos causados por las modificaciones químicas sobre la estabilidad del derivado OC-CALB, se deban a que las modificaciones químicas ocasionaron cambios drásticos en las interacciones entre los residuos que se encuentran sobre la superficie de la CALB y el microambiente que rodea la enzima.

Las modificaciones químicas realizadas sobre el derivado OC-CALB permitieron desarrollar una pequeña librería de biocatalizadores, en algunos casos con una leve hiperactivación frente a un sustrato sintético como el p-NPB y una ligera estabilización bajo ciertas condiciones experimentales. Sin embargo, diferentes estudios encontrados en la literatura (Cabrera et al., 2009; Rodrigues et al., 2011; Galvis et al., 2012) señalan que la modificación química de lipasas es una poderosa herramienta que permite alterar la especificidad de la enzima. Por esta razón, se evaluó la actividad de los derivados modificados de OC-CALB en la hidrólisis del R-mandelato de metilo, sustrato de estructura química más compleja en comparación con el p-NPB.

La Tabla 4 muestra el comportamiento de los diferentes derivados de OC-CALB en la hidrólisis del R-mandelato de metilo a valores de $\mathrm{pH} 5,7$ y 9.
Tabla 4. Actividad de las diferentes preparaciones de OCCALB en la hidrólisis del R-Mandelato de metilo, $10 \mathrm{mM}$ a pH $7 \mathbf{y ~} \mathbf{2 5}^{\circ} \mathbf{C}$. Los experimentos fueron realizados de acuerdo con lo descrito en la sección métodos experimentales.

\begin{tabular}{lccc}
\hline \multirow{2}{*}{ Biocatalizador } & \multicolumn{3}{c}{ Actividad Enzimática } \\
\cline { 2 - 4 } & $\mathbf{p H ~ 5}$ & $\mathbf{p H ~ 7}$ & $\mathbf{p H ~ 9}$ \\
\hline OC-CALB & $44.8 \pm 1$ & $48.4 \pm 1$ & $11.6 \pm 0.5$ \\
\hline OC-CALB-EDA & $22.6 \pm 0.5$ & $30.6 \pm 1.5$ & $9.1 \pm 0.5$ \\
\hline OC-CALB-TNBS & $71.3 \pm 1$ & $33.3 \pm 1$ & $10.9 \pm 0.5$ \\
\hline OC-CALB-TNBS-EDA & $25.2 \pm 1$ & $29.8 \pm 1$ & $11.2 \pm 0.5$ \\
OC-CALB-TNBS-EDA-TNBS & $25.8 \pm 0.5$ & $27.5 \pm 0.5$ & $11 \pm 0.5$ \\
\hline
\end{tabular}

${ }^{a}$ La Actividad se definió como $\mu \mathrm{mol} / \mathrm{g}_{\text {biocatalizador }} / \mathrm{min}$ usando como sustrato R-mandelato de metilo (10mM).

En la Tabla 4, se destaca el derivado OC-CALB por ser el más activo a pH 7 (48U/g) en comparación con los derivados modificados de OC-CALB. Sin embargo, el cambio en el valor de $\mathrm{pH}$ del medio de reacción ocasionó una disminución en la actividad de este derivado. A pH 5, su actividad disminuyó levemente en un factor de 1.1, mientras que a $\mathrm{pH} 9$ decreció 4 veces con respecto a la actividad a pH 7 .

El comportamiento del derivado OC-CALB, fue totalmente diferente cuando se empleó como sustrato el p-NPB (ver Figura 11), en donde exhibió su máxima actividad a $\mathrm{pH}$ 9. Este cambio en el perfil $\mathrm{pH} /$ Actividad de la enzima, es consecuencia de la naturaleza química del sustrato. Mientras el p-NPB es un sustrato neutro, el R-mandelato de metilo tiene un grupo ionizable. Por tanto, la conformación "óptima" que adopte la enzima a un valor de $\mathrm{pH}$ dado, será diferente cuando se use p-NPB o se emplee como sustrato el R-mandelato de metilo. Esto se verá reflejado en un cambio evidente en la especificidad de la enzima hacia uno u otro sustrato (Barbosa et al., 2012).

Por ejemplo, el derivado OC-CALB-EDA es menos activo frente al R-mandelato de metilo a los 3 valores de $\mathrm{pH}$ estudiados, en comparación con la enzima no modificada. Estos resultados contrastan con la alta actividad exhibida por este derivado frente al $\mathrm{p}-\mathrm{NPB}$, principalmente a valores de pH ácidos.

El derivado OC-CALB-TNBS que no mostró cambios drásticos en su actividad frente al $\mathrm{p}$-NPB a los valores de $\mathrm{pH}$ estudiados, incrementó su actividad a pH 5 en un $160 \%$ cuando se empleó como sustrato el R-mandelato de metilo. $\mathrm{A}$ pH 7 disminuyó su actividad 1.45 veces, mientras que a $\mathrm{pH}$ 9 la actividad no sufrió ningún cambio significativo.

La aminación del derivado OC-CALB-TNBS produjo una disminución significativa de la actividad frente al R-mandelato de metilo a pH 5 (alrededor de un factor de 3) con respecto a este mismo derivado no aminado. A pH 7, sufrió una leve 
disminución de la actividad, mientras que a $\mathrm{pH} 9$, el efecto de la modificación con EDA fue despreciable. Además, esta preparación fue menos activa que el derivado de CALB sin modificar excepto a $\mathrm{pH}$ 9. La alteración adicional con TNBS (OC-CALB-TNBS-EDA-TNBS) no causó un efecto significativo sobre la actividad enzimática frente a este sustrato.

Por lo tanto, los resultados obtenidos revelaron que diferentes derivados modificados de la misma lipasa presentan distinta actividad frente a un mismo sustrato; $y$, un mismo derivado presenta diferente actividad frente a distintos sustratos. Además, el efecto del $\mathrm{pH}$ sobre la actividad catalítica de las lipasas también es diferente dependiendo del derivado inmovilizado utilizado.

La propiedad catalítica más interesante de las lipasas es la enantioselectividad (E) frente a sustratos quirales. En este caso, se analizó el efecto de la modificación química sobre la enantioselectividad de los derivados de CALB en la hidrólisis del R y S mandelato de metilo bajo diferentes condiciones de reacción.

Estudios previos realizados en nuestro grupo de investigación han confirmado que esta reacción sigue una cinética de primer orden (hasta una concentración máxima del éster de $100 \mathrm{mM}$ ). Por lo tanto, la enantioselectividad (E) de los diferentes derivados modificados de CALB puede ser determinada como la razón entre la velocidad de reacción del enantiómero $\mathrm{R}$ con la velocidad del enantiómero $\mathrm{S}$.

Bajo las condiciones de estudio a pH 5,7 y 9 a $25^{\circ} \mathrm{C}$ (Tabla 5), todos los derivados modificados de la CALB presentaron una preferencia estereoquímica sobre el enantiómero R.

Los valores de E para cada derivado (Tabla 5) variaron en muchos casos de forma drámatica, con el cambio de $\mathrm{pH}$ del medio de reacción. Por ejemplo, el derivado OC-CALB exhibió su valor máximo de enantioselectividad a $\mathrm{pH} 7(\mathrm{E}=25.5)$; a $\mathrm{pH}$ 9, el valor $\mathrm{E}$ disminuyó en un factor de 2.9 veces $(\mathrm{E}=8.9)$ y a pH 5 disminuyó aproximadamente 2.2 veces $(\mathrm{E}=11.2)$.

La aminación produjo un incremento en la enantioselectividad del derivado OC-CALB-EDA a pH $7(\mathrm{E}=35.6)$ y a $\mathrm{pH} 9$ $(\mathrm{E}=11.4)$ con respecto al derivado no modificado OC-CALB.
Sin embargo, a pH 5 el valor E disminuyó en un factor de 1.5 veces $(E=7.3)$. En este punto, es importante resaltar, el valor E de 35.6 del derivado a $\mathrm{pH} 7$, constituyendo la preparación más enantioselectiva encontrada en este estudio. El resultado sugiere que la modificación con EDA causó una disminución en la actividad del derivado OC-CALB-EDA frente al enantiómero $\mathrm{S}$ a pH 5.

La modificación química con TNBS produjo un aumento en la enantioselectividad del derivado OC-CALB-TNBS a pH 5 de 1.4 veces $(\mathrm{E}=16.2)$ y a $\mathrm{pH} 9$ de 1.7 veces $(\mathrm{E}=15.2)$ con respecto al derivado no modificado. Por su parte, a pH 7 ( $(E=22)$, no se registró alteración en el valor de $E$ en comparación con el derivado OC-CALB.

La aminación adicional del derivado OC-CALB-TNBS, ocasionó que el derivado OC-CALB-TNBS-EDA fuera 7.6 veces menos enantioselectivo a $\mathrm{pH} 5$, que el derivado OC-CALB. A $\mathrm{pH} 9$, la preparación modificada fue 1.4 veces más enantioselectiva que la CALB. Sin embargo, a pH 7, la modificación química no afecto el valor de $\mathrm{E}$ del derivado modificado.

Por su parte, el derivado OC-CALB-TNBS-EDA-TNBS exhibió una enantioselectividad similar a su derivado precursor (OC-CALB-TNBS-EDA) en los 3 valores de $\mathrm{pH}$ estudiados. Este comportamiento es interesante si se considera el cambio drástico que sufre la naturaleza química de la superficie enzimática como consecuencia del aumento de la hidrofobicidad.

Por lo tanto, las modificaciones químicas realizadas sobre la superficie de CALB, produjeron importantes cambios en la enantioselectividad de la enzima bajo diferentes condiciones experimentales. En este sentido, es de resaltar los valores aceptables de enantioselectividad que exhibieron los derivados OC-CALB-TNBS a pH $5(\mathrm{E}=16.2)$ y a $\mathrm{pH} 9(\mathrm{E}=15.2)$, $\mathrm{y}$ de OC-CALB-EDA a pH 7 ( $\mathrm{E}=35.6)$.

\subsection{Modificación Química de Biocatalizadores de CALB con EDA y Anhídrido Succínico}

La caracterización electroforética de los derivados de CALB inmovilizados en octil agarosa y modificados por succinilación

Tabla 5. Enantioselectividad de los derivados modificados de CALB en la hidrólisis del $\mathrm{R}$ y S-mandelato de metilo 10 mM, bajo diferentes condiciones experimentales. Los experimentos fueron realizados de acuerdo con lo descrito en la sección de materiales y métodos

\begin{tabular}{|c|c|c|c|c|c|c|}
\hline \multirow{2}{*}{ Biocatalizador } & \multicolumn{2}{|l|}{ pH 5} & \multicolumn{2}{|l|}{ pH 7} & \multicolumn{2}{|l|}{ pH 9} \\
\hline & Enantio-preferencia & $\mathbf{E}^{\mathbf{a}}$ & Enantio- preferencia & $\mathbf{E}^{\mathbf{a}}$ & Enantio- preferencia & $\mathbf{E}^{\mathbf{a}}$ \\
\hline OC-CALB & $\mathrm{R}$ & $11.2 \pm 0.2$ & $\mathrm{R}$ & $25.5 \pm 0.2$ & $\mathrm{R}$ & $8.9 \pm 0.1$ \\
\hline OC-CAL-EDA & $\mathrm{R}$ & $7.3 \pm 0.1$ & $\mathrm{R}$ & $35.6 \pm 0.2$ & $\mathrm{R}$ & $11.4 \pm 0.1$ \\
\hline OC-CALB-TNBS & $\mathrm{R}$ & $16.2 \pm 0.2$ & $\mathrm{R}$ & $22.2 \pm 0.2$ & $\mathrm{R}$ & $15.2 \pm 0.1$ \\
\hline OC-CALB-TNBS-EDA & $\mathrm{R}$ & $7.6 \pm 0.1$ & $\mathrm{R}$ & $27 \pm 0.3$ & $\mathrm{R}$ & $12.4 \pm 0.1$ \\
\hline OC-CALB-TNBS-EDA-TNBS & $\mathrm{R}$ & $6.1 \pm 0.1$ & $\mathrm{R}$ & $27.5 \pm 0.15$ & $\mathrm{R}$ & $12.2 \pm 0.1$ \\
\hline
\end{tabular}

${ }^{a}$ El valor E se determinó como la razón: Actividad frente a R-mandelato de metilo / Actividad frente a S-metil mandelato. 
al 10\% (OC-CALB-S-10\%), 50\% (OC-CALB-S-50\%) y $100 \%$ (OC-CALB-S-100\%) se realizó mediante electroforesis en condiciones desnaturalizantes y no desnaturalizantes.

En la Figura 12 se muestra el perfil electroforético por SDSPAGE de los derivados de CALB modificados químicamente por succinilación. En ella se puede observar como el proceso de modificación química con anhídrido succínico no causó la formación de dímeros o macromoléculas de la lipasa.

La electroforesis en condiciones no desnaturalizantes (NativaPAGE) (Ver Figura 13) permitió observar que la introducción de grupos carboxilos ionizables sobre la superficie proteica de la enzima, incrementó la densidad de cargas negativas, alterando con ello la carga neta de la CALB. Este efecto fue notable, en los derivados modificados al $50 \%$ y $100 \%$, los cuales presentaron mayores velocidades de migración hacia el ánodo, en comparación con la modificación parcial del $10 \%$ y el derivado de CALB no modificado.

La estabilidad térmica de las distintas preparaciones de OCCALB modificadas químicamente por succinilación, fue evaluada a $70^{\circ} \mathrm{C}$, de acuerdo con lo descrito en la sección de materiales y métodos.

En la Figura 14 se muestra el perfil de inactivación térmica de los diferentes derivados de OC-CALB modificados con anhídrido succínico. Se observa que después de 5 horas de incubación a $70^{\circ} \mathrm{C}$, los derivados de OC-CALB modificados por succinilación al $50 \%$ y $100 \%$, perdieron cerca del $45 \%$ de la actividad inicial. Aun así, fueron 2 veces más estables

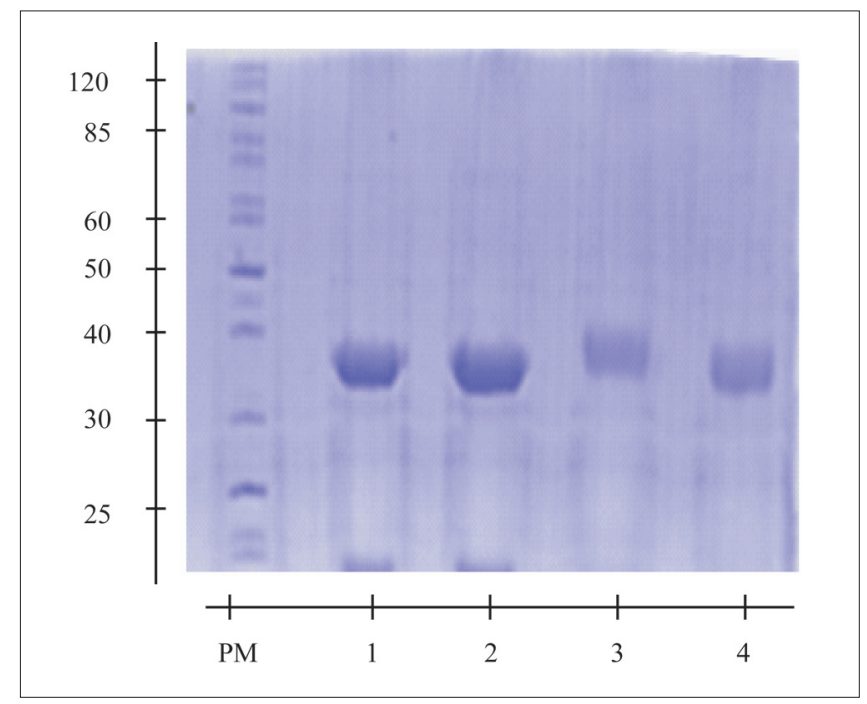

Figura 12. Electroforesis SDS-PAGE de los derivados de OCCALB succinilados.

PM: Marcadores de PM conocido; Carril 1: OC-CALB; Carril 2: OC-CALB-S-10\%; Carril 3: OC-CALB-S-50\%: Carril 4: OCCALB-S-100\%.

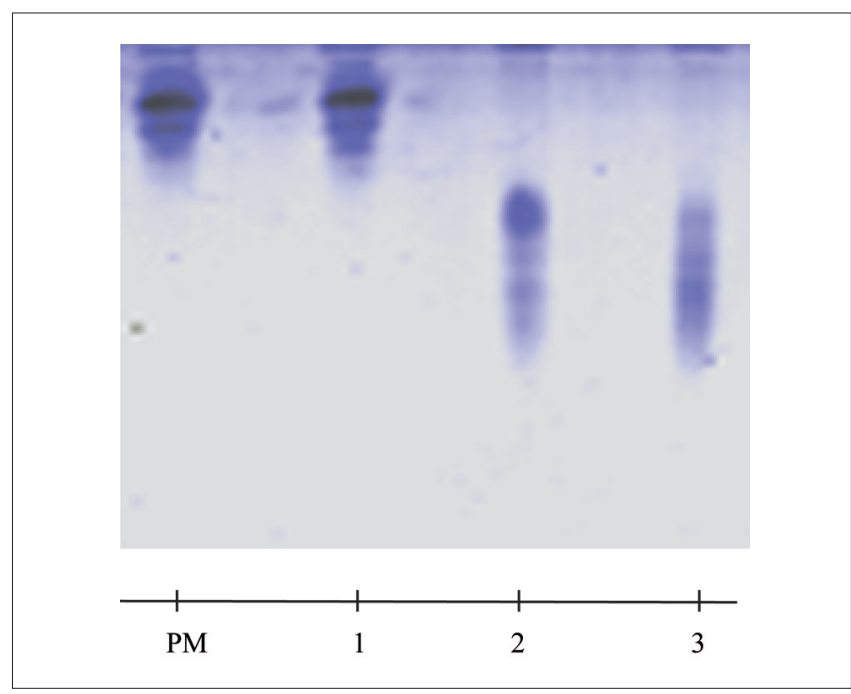

Figura 13. Electroforesis en condiciones No-desnaturalizantes (PAGE-nativa) de los derivados de OC-CALB succinilados. PM: Marcadores de PM conocido; Carril 1: OC-CALB-S-10\%; Carril 2: OC-CALB-S-50\%: Carril 3: OC-CALB-S-100\%

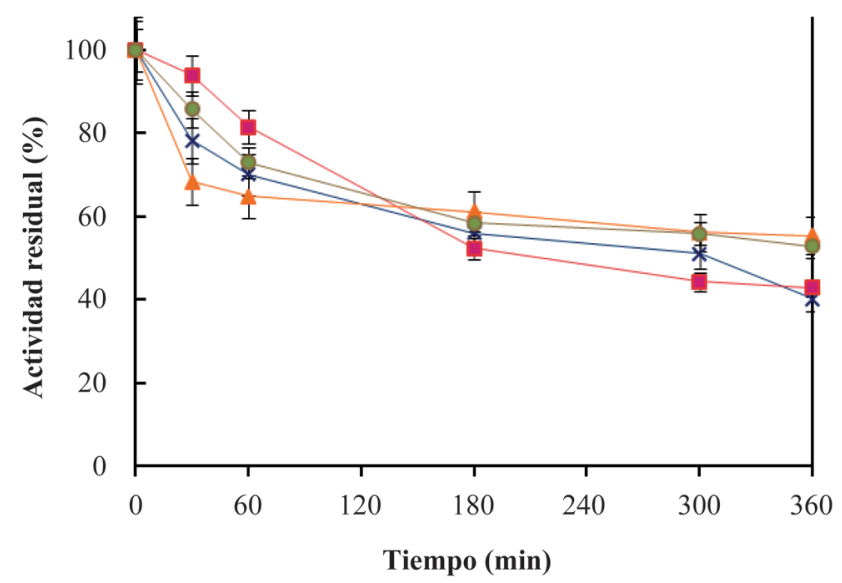

Figura 14. Cursos de inactivación térmica para los diferentes derivados succinilados de CALB. La inactivación térmica se realizó a pH 7 y $70^{\circ} \mathrm{C}$, usando como sustrato p-NPB $0.4 \mathrm{mM}$ para determinar la actividad residual. (X) OC-CALB, ( $)$ OC-CALB-S-10\%, ( $\Delta$ ) OC-CALB-S-50\%, (•) OC-CALB-S-100\%.

que los derivados OC-CALB y OC-CALB-S- $10 \%$, los cuales transcurrido el mismo lapso de tiempo habían perdido el $58 \%$ de su actividad.

Estos resultados sugieren, que los derivados OC-CALB-S-50\% y OC-CALB-S- $100 \%$ son más estables que el derivado OCCALB-S-10\% y que la enzima no modificada. El incremento en la estabilidad de los derivados OC-CALB-S-50\% y OCCALB-S- $100 \%$ se debió quizás a que la introducción de un mayor número de grupos aniónicos sobre la superficie proteíca 
de la CALB, generó nuevas interacciones electrostáticas en zonas de la proteína que pudieron estabilizar una conformación más favorable para la lipasa a la temperatura de estudio (Kotormán et al., 2009).

Los derivados de OC-CALB se aminaron también a diferentes grados de modicación (10, 50 y 100\%). En el proceso de aminación, el efecto de la modificación es más significativo que en la succinilación, debido a la mayor cantidad de grupos carboxilos reactivos en la superficie de CALB en comparación con los grupos amino. En este caso, 16 de los 19 grupos carboxilo totales de la CALB inmovilizada sobre octil agarosa fueron involucrados en la modificación, incluido el grupo carboxilo terminal.

De igual forma el grado de modificación de los derivados OCCALB modificados por aminación, fue controlado mediante la concentración del agente activante (carbodiimida) de los grupos carboxilo en el medio de reacción. El incremento de grupos aminos se comprobó mediante la titulación de los grupos amino primarios disponibles en la enzima mediante el ácido picrilsulfónico (TNBS) (Snyder et al., 1975; Montes et al., 2006). Los derivados de OC-CALB modificados bajo las condiciones descritas en la tabla 10 , se nombraron de acuerdo al grado de modificación así: OC-CALB-EDA-10\%; OC-CALB-EDA- $50 \%$ y OC-CALB-EDA- $100 \%$.

Teniendo en cuenta que la modificación química en ningún caso es completamente específica, algunos grupos, por ejemplo, los grupos hidroxilos de las cadenas laterales de los residuos de tirosinas, pueden ser afectados por la carbodiimida. Sin embargo, esta modificación sobre las tirosinas es revertida mediante la incubación de los derivados en una solución de hidroxilamina, obteniendo así nuevamente las tirosinas libres (Carraway \& Koshland, 1968). Estos derivados incubados en hidroxilamina se nombraron: OC-CALB-EDA-H-10\%; OC-CALB-EDA-H-50\% y OC-CALB-EDA-H-100\%.

Al igual que para la caracterización de los derivados succinilados, los derivados aminados de CALB inmovilizados en octil agarosa, fueron caracterizados mediante estudios electroforéticos en condiciones desnaturalizantes y no desnaturalizantes. La electroforesis en condiciones desnaturalizantes (SDS-PAGE) se realizó para comprobar que el proceso de modificación por aminación de los derivados inmovilizados en octil agarosa CALB, no causaba formación de dímeros y oligómeros de la enzima (Ver Figura 15a).

La electroforesis en condiciones no desnaturalizantes (NativaPAGE) permitió comprobar el cambio en la densidad de carga causado por los diferentes grados de modificación de la CALB inmovilizada en octil agarosa. La Figura 15b muestra que la modificación gradual de los grupos carboxílicos (modificación del 10\%, 50\% y 100\%) altera de la misma forma la movilidad electroforética de la CALB. Lo cual sugiere que el punto isoeléctrico de la enzima se modificó de acuerdo con el grado de modificación realizado. Por ejemplo, la modificación del 10\% de los grupos carboxílicos alteró ligeramente la velocidad de migración de la CALB. La modificación al 50\% ocasionó un incremento en el punto isoeléctrico de la enzima tal vez cercano al $\mathrm{pH}$ del buffer de corrido ( $\mathrm{pH} \mathrm{8)}$. Por su parte, la modificación masiva (100\% de modificación) alteró de forma drástica el punto isoeléctrico de la enzima -de un pI 5.9 a uno por encima de 11- lo cual se vio reflejado en la velocidad de migración en la electroforesis.

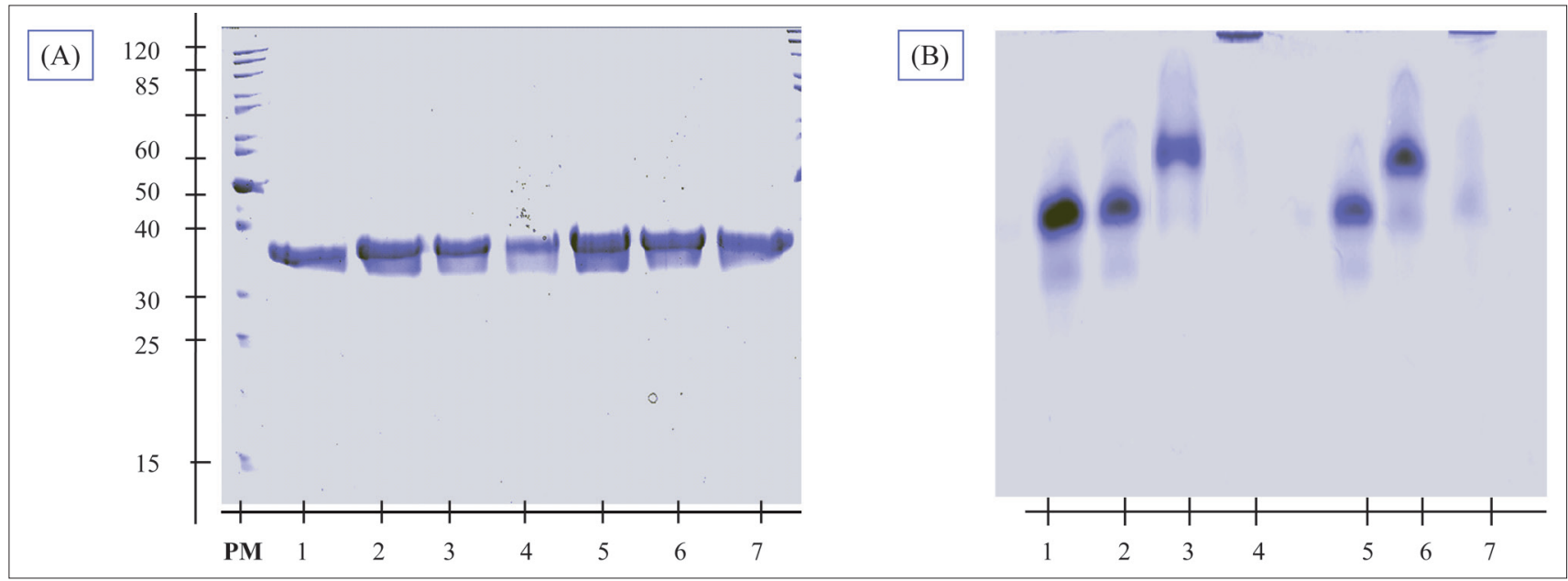

Figura 15. Caracterización electroforética de los derivados de OC-CALB aminados. A) Electroforesis SDS-PAGE. B) Electroforesis nativa-PAGE. Carril PM: Marcador de peso molecular. Carril 1: OC-CALB; Carril 2: OC-CALB-EDA-10\%; Carril 3: OC-CALBEDA-50\%; Carril 4: OC-CALB-EDA-100\%; Carril 5: OC-CALB-EDA-H-10\%; Carril 6: OC-CALB-EDA-H-50\%; Carril 7: OC-CALBEDA-H-100\%. 
Adicionalmente, los derivados de CALB aminados al 10, 50 y $100 \%$ fueron incubados en hidroxilamina con el fin de recuperar los grupos hidroxilo de las cadenas laterales de los residuos de tirosina que pudieron haber sido afectados por la carbodiimida previo a la modificación con EDA. La SDSnativa (Ver Figura 15b) muestra que el tratamiento no afectó la movilidad electroforética de los diferentes derivados.

La aminación gradual de los residuos carboxílicos ionizables en la superficie proteica del derivado OC-CALB no causó un efecto significativo sobre la actividad exhibida por los nuevos derivados obtenidos frente a la hidrólisis del p-NPB (Ver Tabla 6).

En la Tabla 6 se puede observar que los derivados OCCALB-A-10\% y OC-CALB-A-50\% retuvieron el $100 \%$ de la actividad inicial exhibida por el derivado no modificado. Sin embargo, el derivado de la CALB obtenido por la modificación masiva de sus grupos carboxilo (OC-CALBEDA-100\%) incrementó la actividad en un factor de 1.4 veces con respecto mostrada por el derivado no modificado OCCALB. Este incremento notable en la actividad enzimática puede deberse a que el aumento en el número de grupos con carga positiva sobre la superficie enzimática de la CALB (16 grupos catiónicos más por molécula), ocasiona posiblemente un cambio conformacional favorable de la enzima, producto de la alteración de las interacciones electrostáticas presentes en su estructura 3D. Adicionalmente, se pueden estar generando cambios en las interacciones del lid con otros sitios de la proteína, generando así cambios en la forma exacta del centro activo de la lipasa (Palomo et al., 2007; Rodrígues et al., 2009).

Por otra parte, el tratamiento de los diferentes derivados modificados de OC-CALB con hidroxilamina para recuperar las tirosinas que posiblemente se vieron afectadas por la activación con carbodiimida, no afectó significativamente la actividad enzimática exhibida por cada derivado.

El estudio de inactivación de los derivados aminados de OCCALB usando $50 \%(\mathrm{v} / \mathrm{v})$ de solvente orgánico tetrahidrofurano (THF) a $40^{\circ} \mathrm{C}$ (Ver Tabla 7), mostró en general

Tabla 6. Efecto del grado de modificación con EDA sobre la actividad relativa de los derivados de OC-CALB frente al p-NPB. 100 corresponde a la actividad del derivado de CALB no modificado. Los experimentos se realizaron de acuerdo con lo descrito en la sección de métodos analíticos.

\begin{tabular}{lcc}
\hline \multirow{2}{*}{ Derivados } & \multicolumn{2}{c}{ Actividad relativa (\%) } \\
\cline { 2 - 3 } & $\begin{array}{c}\text { Derivados sin tratar } \\
\text { con hidroxilamina }\end{array}$ & $\begin{array}{c}\text { Derivados tratados } \\
\text { con hidroxilamina }\end{array}$ \\
\hline OC-CALB & $100 \pm 3$ & $98 \pm 2$ \\
\hline OC-CALB-EDA-10\% & $100 \pm 7$ & $92 \pm 4$ \\
OC-CALB-EDA-50\% & $100 \pm 2$ & $102 \pm 5$ \\
\hline OC-CALB-EDA-100\% & $140 \pm 5$ & $137 \pm 3$ \\
\hline
\end{tabular}

que la aminación gradual de la CALB con EDA ocasiona posiblemente un cambio conformacional en la estructura 3D de la enzima desfavorable para la estabilidad. Ejemplo de ello, es la disminución en los tiempos de vida media exhibidos por los derivados OC-CALB-EDA-10\%, OCCALB-EDA- $50 \%$ y OC-CALB-EDA- $100 \%$ en comparación con el derivado de la enzima no modificada.

Así, OC-CALB-EDA-10\% fue 1.15 veces menos estable que el derivado no modificado. Por su parte, los derivados OCCALB-EDA-50\% y OC-CALB-EDA-100\% presentaron una estabilidad similar, siendo 3.8 veces menos estables que el derivado OC-CALB.

El tratamiento de los derivados aminados con hidroxilamina para regenerar las tirosinas afectadas por la activación con carbodiimida, permitió recuperar entre un 15 y un $20 \%$ de la estabilidad perdida por la modificación, para los derivados OC-CALB-EDA-50\% y OC-CALB-EDA-100\%. En este estudio, sobresale el incremento en la estabilidad del derivado OC-CALB-EDA-10\%, el cual no solo recuperó el 100\% de la estabilidad sino que fue 2.13 veces más estable que el derivado no modificado.

Los resultados sugieren que los grupos hidroxilo regenerados en las tirosinas ( 5 residuos accesibles al medio) forman tal vez interacciones adicionales de tipo puente de hidrógeno con el medio de reacción y con otros aminoácidos próximos en la superficie proteica que estabilizan más la conformación adquirida por la enzima modificada con grupos amino (Rodrigues et al., 2011; Galvis et al., 2012).

La Tabla 7, resume los tiempos de vida media de los diferentes derivados de OC-CALB aminados gradualmente con EDA, al ser incubados en tetrahidrofurano $50 \%(\mathrm{v} / \mathrm{v})$.

La propiedad catalítica más interesante de las lipasas es la enantioselectividad frente a sustratos quirales. En este caso, se analizó el efecto de la inmovilización y la modificación con etilendiamina y anhídrido succínico sobre la actividad y enantioselectividad de la CALB en la hidrólisis de (R) y (S)-mandelato de metilo.

Tabla 7. Tiempos de vida media (horas) de los diferentes derivados modificados de OC CALB en presencia de tetrahidrofurano $50 \%$ (v/v) / buffer Tris-HCl 50mM de pH 7 a $\mathbf{4 0}^{\circ} \mathrm{C}$. Los experimentos se realizaron de acuerdo a lo descrito en la sección de métodos experimentales.

\begin{tabular}{lcc}
\hline \multirow{2}{*}{ Derivados } & \multicolumn{2}{c}{ Tiempos de vida media (h) } \\
\cline { 2 - 3 } & $\begin{array}{c}\text { Derivados sin tratar } \\
\text { con hidroxilamina }\end{array}$ & $\begin{array}{c}\text { Derivados tratados } \\
\text { con hidroxilamina }\end{array}$ \\
\hline OC-CALB & 1.5 & 1.5 \\
\hline OC-CALB-EDA-10\% & 1.3 & 3.2 \\
OC-CALB-EDA-50\% & 0.4 & 0.3 \\
\hline OC-CALB-EDA-100\% & 0.4 & 0.7 \\
\hline
\end{tabular}


Tabla 8. Efecto de la naturaleza del soporte y la modificación química en fase sólida con etilendiamina y anhídrido succínico sobre la enantioselectividad de la CALB catalizando la hidrólisis de (R) y (S)-mandelato de metilo $10 \mathrm{mM}, \mathrm{pH} 7$.

\begin{tabular}{lcc}
\hline Derivados & Enantiopreferencia & $\mathbf{E}^{*}$ \\
\hline OC-CALB & $\mathrm{R}$ & $25.5 \pm 0.2$ \\
\hline OC-CALB-EDA-100\% & $\mathrm{R}$ & $35.6 \pm 1.2$ \\
OC-CALB-S-100\% & $\mathrm{R}$ & $16.3 \pm 0.5$ \\
\hline EC-CALB & $\mathrm{R}$ & $7.5 \pm 0.7$ \\
EC-CALB-EDA-100\% & $\mathrm{R}$ & $16.6 \pm 1$ \\
\hline EC-CALB-S-100\% & $\mathrm{R}$ & $13.2 \pm 0.8$ \\
\hline
\end{tabular}

* El valor E se determinó como la razón: Actividad frente a R-mandelato de metilo / Actividad frente a S-metil mandelato.

La enantioselectividad de la CALB en la hidrólisis del (R) y (S)-mandelato de metilo, se vio afectada tanto por la estrategia de inmovilización como por la modificación química realizada (Ver Tabla 8). Por ejemplo, el derivado OC-CALB-EDA- $100 \%$ fue 2.2 veces y 1.4 veces más enantioselectivo que los derivados OC-CALB-S-100\% y OC-CALB, respectivamente.

Con el cambio en la naturaleza química del soporte y la orientación de la enzima sobre el mismo, la enantioselectividad de la CALB se vio afectada de manera dramática. Por ejemplo, la disminución de la enantioselectividad del derivado EC-CALB-EDA- $100 \%$ en un factor de 2.2 veces en comparación con el derivado OC-CALB-EDA- $100 \%$. Sin embargo, es de resaltar que la enantioselectividad del derivado EC-CALB se incrementó en un factor de 2.2 veces debido a la aminación con EDA y 1.8 debido a la succinilación.

Por lo tanto, los resultados obtenidos confirman que el efecto de la modificación química en fase sólida sobre las propiedades biocataliticas de CALB es dependiente de la zona de la proteína involucrada en el proceso de inmovilización y de la rigidez que adopte su estructura 3D sobre la superficie del soporte (Cabrera et al., 2009; Forde et al., 2010; DiazRodriguez \& Davis, 2011).

\section{Conclusiones}

En este trabajo se muestra que la modificación química de enzimas es una herramienta interesante para modificar sus propiedades bioquímicas. Además, se demostró que la misma modificación química en enzimas inmovilizadas en diferentes soportes puede producir diferentes efectos en sus propiedades bioquímicas. Esto sugiere que la combinación de diferentes protocolos y de tipos de modificación química puede generar una librerúa de nuevos biocatalizadores incluso usando sólo una enzima.
Se ha usado como modelo la enzima CALB, la cual fue interfacialmente activada o inmovilizada de forma covalente en soportes poliméricos. A través de modificaciones químicas con EDA, TNBS o anhídrido succínico, se mejoró, en algunos casos, su estabilidad a la temperatura y a mezclas del solvente orgánico. Estas preparaciones fueron más estables que la preparación de CALB inmovilizada en octil-agarosa, Eupergit C $\mathrm{y}$ agarosa-BrCN no-modificadas.

Las modificaciones químicas ensayadas en este trabajo produjeron biocatalizadores con muy diferentes actividades, especficidades y enantioselectividades, permitiendo en algunos casos mejorar el valor de razón enantiomérica (E) de CALB en la hidrólisis de (R/S)-mandelato de metilo bajo diferentes condiciones experimentales, lo cual sugiere que estas modidicaciones podrían tener un alto interés en modular sus propiedades en otros procesos enantioespecíficos.

\section{Agradecimientos}

Primero que todo, quisiera agradecer el haber tenido la oportunidad de poder trabajar y contar con el soporte brindado durante los últimos 15 años por estudiantes, colegas y profesores durante mi vida académica en Colombia. Deseo agradecer el apoyo prestado por mi colega y compañera, la doctora Claudia Ortiz, por su participación constante en el desarrollo de la línea de biocatálisis y biotransformaciones como directora del Grupo de Investigación en Bioquímica y Microbiología (GIBIM) de la Universidad Industrial de Santander. Al profesor de Investigación del CSIC, Roberto Fernández-Lafuente, por su colaboración en la formación de estudiantes de doctorado de nuestro grupo de investigación y su notable aporte al campo de la biocatálisis. Al Doctor Luis Oveimar Barbosa, por su aporte experimental a los resultados de esta investigación. A las químicas Magaly Galvis y Mónica Ruiz, por su esfuerzo y tenacidad al haber incursionado en el campo de la bioquímica experimental. Quisiera agradecer también el apoyo brindado por Colciencias (Proyecto $\mathrm{N}^{\circ}$ 1102-489-25428), la Vicerrectoria de Investigación y Extensión (VIE) de la Universidad Industrial de Santander (UIS) y el Ministerio de Economía y Competitividad de España (Proyecos CTQ2012-31855) quienes han aportado a la financiación de este trabajo, así como el patrocinio de la compañía Novozymes, especialmente a través de la ingeniera Sandra La-Rotta (Coldanzimas Ltda) proveyendo las enzimas para el desarrollo de este trabajo de investigación.

\section{Bibliografía}

Adlercreutz, P. 2013. Immobilisation and application of lipases in organic media. Chem Soc Rev. 42: 6406-6436.

Ahmed, M.; Kelly, T. \& Ghanem, A. 2012. Applications of enzymatic and non-enzymatic methods to access enantiomerically pure compounds using kinetic resolution and racemization. Tetrahedron. 68 (34): 6781-6802. 
Anderson, E.; Larsson, K. \& Kirk, O. 1998. One BiocatalystMany Applications: The Use of Candida antarctica B-Lipase in Organic Synthesis. Biocat Biotrans. 16 (3): 181-204.

Aravindan, R.; Anbumathi, P. \& Viruthagiri, T. 2007. Lipase applications in food industry. Indian J Biotechnol. 6: 141158.

Barbosa, O.; Ariza, C.; Ortiz, C. \& Torres, R. 2010. Kinetic resolution of $(\mathrm{R} / \mathrm{S})$-propranolol (1-isopropylamino-3(1-naphtoxy)-2-propanolol) catalyzed by immobilized preparations of Candida antarctica lipase B (CAL-B)". New Biotechnol. 27 (6): 844-850.

Barbosa, O.; Ortiz, C.; Torres, R. \& Fernández-Lafuente, R. 2011. Effect of the immobilization protocol on the properties of lipase B from Candida antarctica in organic media: Enantiospecific production of atenolol acetate. J Mol Catal B: Enzym. 71: 124-132.

Barbosa, O.; Ruiz, M.; Ortiz, C.; Fernández, M.; Torres, R.; Fernandez-Lafuente, R. 2012. Modulation of the properties of immobilized CALB by chemical modification with 2,3,4trinitrobenzenesulfonate or ethylendiamine. Advantages of using adsorbed lipases on hydrophobic supports. Process Biochem. 47: 867-876.

Barros M, Fleuri L, Macedo G. 2010. Seed lipases: sources, applications and properties: a review". Brazil J Chem Eng. 27 (1): 15-29.

Baslé, E.; Joubert, N. \& Pucheault, M. 2010. Protein chemical modification on endogenous amino acids. Chem Biol. 17: 213-227.

Bastida, A.; Sabuquillo, P.; Armisén, P.; Fernández-Lafuente, R.; Huguet, J. \& Guisan, J.M. 1998. A single step purification, immobilization, and hyperactivation of lipases via interfacial adsorption on strongly hydrophobic supports. Biotechnol Bioeng. 58: 486-493.

Berglund, P. 2001. Controlling lipase enantioselectivity for organic synthesis. Biomol Eng. 18: 13-22.

Betancor, L.; López-Gallego, F.; Hidalgo, A.; Alonso-Morales, N.; Mateo, C.; Dellamora-Ortiz, G.; et al. 2006. Different mechanisms of protein immobilization on glutaraldehyde activated supports: effect of support activation and immobilization conditions. Enzyme Microb Technol. 39: 877-382.

Bradford, M.M. 1976. Rapid and sensitive method for the quantitation of microgram quantities of protein utilizing the principle of protein-dye binding. Anal. Biochem. 72: 248-254.

Brady, L.; Brzozowski, A.; Derewenda, Z.; Dodson, E. \& Dodson, G. 1990. A serine protease triad forms the catalytic center of a triacylglycerol lipase". Nature. 343: 767-770.

Brzozowski, A.; Derewenda, Z.; Derewenda, U.; Dodson, G. \& Lawson, D.M. 1991. A model for interfacial activation in lipases from the structure of a fungal lipase-inhibitor complex. Nature. 351: 491-494.

Cabrera, Z.; Fernandez-Lorente, G.; Fernandez-Lafuente, R.; Palomo, J.M. \& Guisan, J.M. 2009. Enhancement of
Novozym-435 catalytic properties by physical or chemical modification. Process Biochem. 44: 226-231.

Cantone, S.; Hanefeld, U. \& Basso, A. 2007. Biocatalysis in nonconventional media-ionic liquids, supercritical fluids and the gas phase. Green Chem. 9: 954-971.

Carraway, K.L. \& Koshland Jr, D.E. 1968. Reaction of tyrosine residues in proteins with carbodiimide reagents. Biochem Biophys Acta 160: 272-4.

Carraway, K.L. \& Koshland Jr DE. 1972. Carbodiimide modification of proteins. Methods Enzymol. 25:616-23.

Carraway, K.L.; Spoerl, P. \& Koshland Jr, D.E. 1969. Carboxyl group modification in chymotrypsin and chymotrypsinogen. J Mol Biol. 42: 133-137.

Casas-Godoy, L.; Duquesne, S.; Bordes, F.; Sandoval, G. \& Marty, A. 2012. Lipases: An overview. Methods Mol Biol. 861: $3-30$.

Chalker, J.M.; Bernardes, G.J.L.; Lin, Y.A. \& Davis, B.G. 2009. Chemical modification of proteins at cysteine: opportunities in chemistry and biology. Chem Asian J. 4: 630-640.

Chen, C.; Fujimoto, Y.; Girdaukas, G. \& Sih, C. 1982. General Aspects and Optimization of Enantioselective Biocatalysis. In: Organic Solvents: The Use of Lipases. J Am Chem Soc. 104: 7294-7299.

Chiang, C-J; Chern, J-T; Wang, J-Y\& Chao, Y-P. 2008. Facile immobilization of evolved Agrobacterium radiobacter carbamoylase with high thermal and oxidative stability. J Agric Food Chem. 56: 6348-6354.

Dash, C.; Phadtare, S.; Deshpande, V. \& Rao, M. 2001. Structural and mechanistic insight into the inhibition of aspartic proteases by a slow-tight binding inhibitor from an extremophilic Bacillus sp.: correlation of the kinetic parameters with the inhibitor induced conformational changes. Biochemistry. 40: 11525-32.

Davis, B.G.; Shang, X.; DeSantis, G.; Bott, R.R. \& Jones, J.B. 1999. The controlled introduction of multiple negative charge at single amino acid sites in subtilisin Bacillus lentus. Bioorg Med Chem. 7: 2293-2301.

Davis, B.G. 2003. Chemical modification of biocatalysts. Curr Opin Biotechnol.14: 379-386.

De Santis, G. \& Jones, J. 1999. Chemical modification of enzymes for enhanced functionality. Curr Opin Biotechnol. 10: 324330 .

Desnuelle P. 1972. The Enzymes. 3rd Editorial Boyer, Academic Press, NY, 575.

Derewenda, U.; Brzozowski, A.; Lawson, D. \& Derewenda, Z.S. 1992. Catalysis at the interface: the anatomy of conformational change in a triglyceride lipase. Biochemistry. 31: $1532-1541$

Díaz-Rodríguez, A. \& Davis, B.G. 2011. Chemical modification in the creation of novel biocatalysts. Curr Opin Chem Biol. 15 (2): 211-219. 
Durand, J.; Teuma, E. \& Gómez, M. 2007. Ionic liquids as a medium for enantioselective catalysis. C R Chim. 10: 152177.

Ericsson, J.; Kasrayan, A.; Johansson, P.; Bergfors, T. \& Mowbray, L. 2008. X-ray Structure of Candida antarctica Lipase A Shows a Novel Lid Structure and a Likely Mode of Interfacial Activation. J Mol Biol. 376: 109-119.

Fernandez-Lafuente, R.; Rosell, C.M.; Alvaro, G. \& Guisan, J.M. 1992. Additional stabilization of penicillin G acylaseagarose derivatives by controlled chemical modification with formaldehyde. Enzyme Microb Technol. 14: 489-495.

Fernandez-Lafuente, R.; Rosell, C.M.; Rodriguez, V. \& Guisan, J.M. 1995. Strategies for enzyme stabilization by intramolecular crosslinking with bifunctional reagents. Enzyme Microb Technol. 17: 517-23.

Fernandez-Lafuente, R. 2009. Stabilization of multimeric enzymes: strategies to prevent subunit dissociation. Enzyme Microb Technol. 45: 405-418.

Fernández-Lorente, G.; Palomo, J.M.; Cabrera, Z.; Guisán,J.M. \&Fernández-Lafuente, R. 2007. Specificity enhancement towards hydrophobic substrates by immobilization of lipases by interfacial activation on hydrophobic supports. Enzyme Microb Technol 41: 565-569.

Fernandez-Lorente, G.; Godoy, C.A.; Mendes, A.A.; LopezGallego, F.; Grazu, V.; de las Rivas, B., et al. 2008. Solid-phase chemical amination of a lipase from Bacillus thermocatenulatus to improve its stabilization via covalent immobilization on highly activated glyoxyl-agarose. Biomacromolecules. 9: 2553-2561.

Ferrer, M.; Golyshina, O.; Beloqui, A. \& Golyshin, P.N. 2007. Mining enzymes from extremes environments. 10 (3): 207214.

Fjerbaek, L.; Christensen, K.V. \& Norddahl, B. 2009. A review of the current state of biodiesel production using enzymatic transesterification. Biotechnol Bioeng. 102: 1298-1315.

Forde, J.; Vakurov, A.; Gibson, T.D.; Millner, P.; Whelehan, M.; Marison, I.W.; et al. 2010a. Chemical modification and immobilisation of lipase B from Candida antarctica onto mesoporous silicates. J Mol Catal B: Enzym. 66: 203-209.

Forde, J.; Tully, E.; Vakurov, A.; Gibson, T.D.; Millner, P. \& Ó'Fágáin, C. 2010b. Chemical modification and immobilisation of laccase from Trametes hirsuta and from Myceliophthora thermophila. Enzyme Microb Technol. 46: 430-437.

Galvis, M.; Barbosa, O.; Ruiz, M.; Cruz, J.; Torres, R.; Ortiz, C. \& Fernandez-Lafuente, R. 2012. Chemical amination of lipase B from Candida antarctica is an efficient solution for the preparation of crosslinked enzyme aggregates. Proc Biochem. 47: 2373-2378.

Gandhi, N.N. 1997. Applications of lipase. J Am Oil Chem Soc. 74: 621-634.
Gotor-Fernández, V.; Brieva, R. \& Gotor, V. 2006a. Lipases: Useful biocatalysts for the preparation of pharmaceuticals. J Mol Catal B: Enz. 40: 111-120.

Gotor-Fernández, V.; Busto, E. \& Gotor, V. 2006b. Candida antarctica lipase B: an ideal bio- catalyst for the preparation of nitrogenated organic compounds. Adv Synth Catal 348 797-812.

Grochulski, P.; Li, Y.; Schragm, J.; Boutthilier, F.; Smith, P.; Harrinson, D.; Rubin, B. \& Cyler, M. 1993. Insights into interfacial activation from an open structure of Candida rugosa lipase". J Biol Chem. 268: 12843-12847.

Gron, H.; Bech, L.M.; Branner, S. \& Breddam, K. 1990. A highly active and oxidation- resistant subtilisin-like enzyme produced by a combination of site-directed mutagenesis and chemical modification. Eur J Biochem. 194: 897-901.

Gupta, M.N. \& Roy, I. 2004. Enzymes in organic media: forms, functions and applications. Eur J Biochem. 271: 2575-2583.

Hacking, M.; Van Rantwijk, F. \& Sheldon, R. 2000. Lipase catalysed synthesis of diacyl hydrazines: An indirect method for kinetic resolution of chiral acids. J Mol Catal B: Enz. 9 (4-6): 183-191.

Hernandez, K. \& Fernández-Lafuente, R. 2011. Control of protein immobilization. Coupling immobilization and site directed mutagenesis to improve biocatalyst or biosensor performance. Enzyme Microb Technol. 48: 107-122.

Hernandez, K.; Garcia-Verdugo, E.; Porcar, R. \& FernandezLafuente, R. 2011. Hydrolysis of triacetin catalyzed by immobilized lipases: Effect of the immobilization protocol and experimental conditions on diacetin yield". Enz Microb Technol. 48 (6-7): 510-517.

Husain, S.; Jafri, F. \& Saleemuddin, M. 1996. Effects of chemical modification on the stability of invertase before and after immobilization. Enzyme Microb Technol. 18: 275-80.

Itoh, T. 2009. Recent development of enzymatic reaction systems using ionic liquids. J Synth Org Chem. 67: 143-155.

Iwasaki, Y. \& Yamane, T. 2000. Enzymatic synthesis of structured lipids. J Mol Catal B: Enzyme. 10: 129-140.

Jäckel, C.; Kast, P. \& Hilvert, D. 2008. Protein design by directed evolution. Ann Rev Biophys. 37: 153-173.

Jaeger, K.E. \& Reetz, M.T. 1998. Microbial lipases from versatile tools for biotechnology. Trends Biotechnol. 16: 396-403.

Jagtap, S. \& Rao, M. 2006. Conformation and microenvironment of the active site of a low molecular weight 1,4-beta-Dglucan glucanohydrolase from an alkalothermophilic Thermomonospora $s p$.: involvement of lysine and cysteine residues. Biochem Biophys Res Commun. 347: 428-32.

Juhl, P.; Doderer, K.; Hollmann, F.; Thum, O. \& Pleiss, J. 2010. Engineering of Candida antarctica lipase B for hydrolysis of bulky carboxylic acid esters. J Biotechnol. 150 (4): $474-480$ 
Khajeh, K.; Naderi-Manesh, H.; Ranjbar, B.; MoosaviMovahedi, A.A. \& Nemat- Gorgani, M. 2001. Chemical modification of lysine residues in Bacillus alpha-amylases: effect on activity and stability. Enzyme Microb Technol. 28: 543-549.

Kirk, O. \& Christensen, M. 2002. Lipases from Candida antarctica: Unique Biocatalysts from a Unique Origin". Organic Process Research and Development. 6: 446-451.

Kohn, J. \& Wilchek, M. 1982. A new approach (cyano-transfer) for cyanogen bro- mide activation of sepharose at neutral $\mathrm{pH}$, which yields activated resins, free of interfering nitrogen derivatives. Biochem Biophys Res Commun. 107: 878-884.

Kolodziejska, R.; Karczmarska-Wódzka, A.; Wolan, A. \& Dramiński, M. 2012. Candida antarctica lipase B catalyzed enantioselective acylation of pyrimidine acyclonucleoside". Biocat Biotrans. 30 (4): 426-430.

Kotormán, M.; Cseri, A.; Laczkó, I. \& Simon, LM. 2009. Stabilization of $\alpha$-chymotrypsin in aqueous organic solvents by chemical modification with organic acid anhydrides. J Mol Catal B: Enzym. 59 (1-3): 153-157.

Kurtovic, S. \& Mannervik, B. 2009. Identification of emerging quasi-species in directed enzyme evolution. Biochemistry. 48: $9330-9339$.

Laemmli, U.K. 1970. Cleavage of structural proteins during the assembly of the head of bacteriophage T4. Nature. 227: 680685.

Mansfeld, J.; Vriend, G.; Van Den Burg, B.; Eijsink, V.G.H. \& Ulbrich-Hofmann, R. 1999. Probing the unfolding region in a thermolysin-like protease by site-specific immobilization. Biochemistry. 38: 8240-8245.

March, S.C.; Parikh, I. \& Cuatrecasas, P. 1974. A simplified method for cyanogen bromide activation of agarose for affinity chromatography. Anal Biochem. 60: 149-152.

Marciello, M.; Filice, M. \& Palomo, J.M. 2012. Different strategies to enhance the activity of lipase catalysts. Cat Sci Technol. 2: 1531-1543.

Martinelle, M.; Holmquist, M. \& Hult, K. 1995. On the interfacial activation of Candida Antarctica lipase A and B as compared with Humicola lanuginose lipase. Biochim Biophys Acta. 1258: $272-276$.

Mateo, C.; Fernández-Lorente, G.; Abian, O.; FernándezLafuente, R. \& Guisán, J.M. 2000. Multifunctional epoxy supports: A new tool to improve the covalent immobilization of proteins. The promotion of physical adsorptions of proteins on the supports before their covalent linkage. Biomacromolecules. 1: 739-745.

Mateo, C.; Abian, O.; Bernedo, M.; Cuenca, E.; Fuentes, M.; Fernandez-Lorente, G.; et al. 2005. Some special features of glyoxyl supports to immobilize proteins. Enzyme Microb Technol. 37: 456-462.
Mateo, C.; Palomo, J.M.; Fernández-Lorente, G.; Guisan, J.M. \& Fernandez-Lafuente, R. 2007a. Improvement of enzyme activity, stability and selectivity via immobilization techniques. Enzyme Microb Technol. 40: 1451-1463.

Mateo, C.; Grazú, V.; Pessela, B.; Montes, T.; Palomo, J.M.; Torres, R.; López-Gallego, F.; Fernández-Lafuente, R. \& Guisán, J.M. 2007b. Advances in the design of new epoxy supports for enzyme immobilization-stabilization. Biochem Soc Trans. 35: 1593-1601.

Matsumoto, K.; Davis, B.G. \& Jones, J.B. 2002. Chemically modified "polar patch" mutants of subtilisin in peptide synthesis with remarkably broad substrate acceptance: designing combinatorial biocatalysts. Chem Eur J. 8: 41294137.

Mendes, A.A.; De Castro, H.F.; De, S.; Rodrigues, D.; Adriano, W.S.; Tardioli, P.W., et al. 2011. Multipoint covalent immobilization of lipase on chitosan hybrid hydrogels: influence of the polyelectrolyte complex type and chemical modification on the catalytic properties of the biocatalysts. $\mathrm{J}$ Ind Microbiol Biotechnol. 38: 1055-1066.

Meyer, H-P. 2006. Chemocatalysis biocatalysis (biotransformation): some thoughts of a chemist and of a biotechnologist. Org Process Res Dev. 10: 572-580.

Montes, T.; Grazú, V.; Lopez-Gallego, F.; Hermoso, J.; Guisán, J.M. \& Fernandez-Lafuente R. 2006. Chemical modification of protein surfaces to improve their reversible enzyme immobilization on ionic exchangers". Biomacromolecules. 11: $3052-3058$.

Nobel, M.; Cleasby, A.; Johnson, L.; Egmond, M. \& Frenken, G. 1993. The crystal structure of triacylglycerol lipase from Pseudomonas glumae reveals a partially redundant catalytic aspartate. FEBS Lett. 331: 1265-1269.

O'Fágáin, C. 2003. Enzyme stabilization- recent experimental progress. Enzyme Microb Technol. 33: 137-149.

Ortega, S.; Máximo, M.; Montiel, M.; Murcia, M. \& Bastida, J. 2012. Esterification of polyglycerol with polycondensed ricinoleic acid catalysed by immobilised Rhizopus oryzae lipase. Bioprocess Biosyst Eng. 36: 1291-1302.

Ortiz-Soto, M.E.; Rudiño-Piñera, E.; Rodriguez-Alegria, M.E. \& Munguia, A.L. 2009. Evaluation of cross-linked aggregates from purified Bacillus subtilis levansucrase mutants for transfructosylation reactions. BMC Biotechnol. 9: 68.

Overbeeke, P.; Govardhan, C.; Khalaf, N.; Jongejan, J. \& Heijnen, J. 2000. Influence of lid conformation on lipase enantioselectivity. J Mol Catal B: Enzym. 10 (4): 385-393.

Palomo, J.M.; Fernández-Lorente, G.; Guisán, J.M. \& Fernández-Lafuente, R. 2007. Modulation of immobilized lipase enantioselectivity via chemical amination. Adv Synth Catal. 349: 1119-27.

Palomo, J.M. 2010. Diels-Alder cycloaddition in protein chemistry. Eur J Org Chem. 33: 6303-6314. 
Palomo, J.M. \& Guisan, J.M. 2012. Differnt strategies for hyperactivation of lipase biocastalysts. Methods Mol Biol. 861: $329-341$.

Pandey, A.; Benjamin, S.; Soccol, C.R.; Nigam, P.; Krieger, N. \& Soccol, V.T. 1999. The realm of microbial lipases in biotechnology. Biotechnol Appl Biochem. 29: 119-131.

Pedroche, J.; del Mar Yust, M.; Mateo, C.; Fernández-Lafuente, R.; Girón-Calle, J.; Alaiz, M.; et al. 2007. Effect of the support and experimental conditions in the intensity of the multipoint covalent attachment of proteins on glyoxylagarose supports: correlation between enzyme-support linkages and thermal stability. Enzyme Microb Technol. 40: 11601166.

Peterson, A.E.; Adlercrutz, P. \& Mattiason, B. 2007. A water activity control system for enzymatic reactions in organic media. Biotechnol Bioeng. 97: 235-241.

Polizzi, K.M.; Bommarius, A.S.; Broering, J.M. \& ChaparroRiggers, J.F. 2007. Stability of bio-catalysts. Curr Opin Chem Biol. 11: 220-5.

Pollard, D.J. \& Woodley, J.M. 2007. Biocatalysis for pharmaceutical intermediates: the future is now. Trends Biotechnol. 25: 66-73.

Prechter, A.; Gröger, H. \& Heinrich, M. 2012. Synthesis of (S)$(+)$-cericlamine through lipase-catalyzed aminolysis of azo acetates. Org Biomol Chem. 17 (10): 3384-3387.

Quinn, D.M.; Shirai, K.; Jackson, R.L. \& Harmony, J.A. 1982. Lipoprotein lipase catalyzed hydrolysis of water-soluble p-nitrophenyl esters. Inhibition by apoliporotein C-II. Biochemistry. 21 (26): 6872-6879.

Rao, M.N.; Kembhavi, A.A. \& Pant, A. 1996. Role of lysine, tryptophan and calcium in the beta-elimination activity of a low-molecular-mass pectate lyase from Fusarium moniliformae. Biochem J. 319: 159-164.

Ray, J.; Nagy, Z.; Smith K.; Bhaggan, K. \& Stapley, A. 2013. Kinetic study of the acidolysis of high oleic sunflower oil with stearic-palmitic acid mixtures catalysed by immobilised Rhizopus oryzae lipase. Biochem Eng J. 73: 17-28.

Reetz, M.T. 2002. Lipases as practical biocatalysts. Curr Opin Chem Biol 6: 145-150.

Reetz, M.T. 2007. Controlling the selectivity and stability of proteins by new strategies in directed evolution: the case of organocatalytic enzymes. Ernst Schering Found Symp Proc 2007: $321-340$

Rehm, S.; Trodler, P. \& Pleiss, J. 2011. Solvent-induced lid opening in lipases: A molecular dynamics study. Protein Science. 19 (11): 2122-2130.

Reis, P.; Miller, P.; Kragel, K. \& Leser, M, et al. 2008. Lipases at Interfaces: Unique Interfacial Properties as Globular Proteins. Langmuir. 24: 6812-6819.

Reis, P.; Holmberg, K.; Watzke, H.; Leser, M. \& Miller, R. 2009. Lipases at interfaces: A review. Adv Colloid Interface Sci. 147-148 (C): 237-250.
Rodrigues, R.C:; Ortiz, C., Berenguer-Murcia, A.; Torres, R. \& Fernández-Lafuente, R. 2013. Modifying enzyme activity and selectivity by immobilization. RSC. 42, 6290-6307.

Rodrigues, R.C.; Berenguer-Murcia, A. \& FernandezLafuente, R. 2011. Coupling chemical modification and immobilization to improve the catalytic performance of enzymes. Adv Synth Catal. 353: 2216-2238.

Rodrigues, R.C.; Godoy, C.A.; Volpato, G.; Ayub, M.A.Z.; Fernandez-Lafuente, R. \& Guisan, J.M. 2009. Immobilization-stabilization of the lipase from Thermomyces lanuginosus: critical role of chemical amination. Process Biochem. 44: 963-968.

Samuelson, J.C. 2011. Recent developments in difficult protein expression: a guide to $E$. coli strains, promoters, and relevant host mutations. Methods Mol Biol. 705: 195-209.

Santaniello, E.; Casati, S. \& Ciuffreda, P. 2006. LipaseCatalyzed Deacylation by Alcoholysis: A Selective, Useful transesterification reaction. Curr Org Chem. 10 (10): 1095 1123.

Sarda, L. \& Desnuelle, P. 1958. Actions of pancreatic lipase on esters in emulsions. Biochim Biophys Acta. 30 (3): 513-521.

Secundo, F.; Carrea, G.; Tarabiono, C.; Gatti-Lafranconi, P.; Brocca, S.; Lotti, M.; Jaeger, K.; Puls, M. \& Eggert, T. 2006. The lid is a structural and functional determinant of lipase activity and selectivity". Journal of Molecular Catalysis B: Enzymatic. 39: 166-170.

Schmid, A.; Dordick, J.S.; Hauer, B.; Kiener, A.; Wubbolts, M. \& Witholt, B. 2001. Industrial biocatalysis today and tomorrow. Nature. 409: 258-268.

Schmidt, M.; Böttcher, D. \& Bornscheuer, U.T. 2009. Protein engineering of carboxyl esterases by rational design and directed evolution. Protein Pept Lett. 16: 1162-1171.

Schoemaker, H.E.; Mink, D. \& Wubbolts, M.G. 2003. Dispelling the myths - biocatalysis in industrial synthesis. Science. 99 1694-1697.

Sharma, D.; Sharma, B. \& Shukla, A.K. 2011. Biotechnological approach of microbial lipase: A review. Biotechnology. 10: $23-40$.

Sheldon, R.A. 2005. Green solvents for sustainable organic synthesis: state of the art. Green Chem. 7: 267-278.

Smith, D.W. 1996. Problems of translating heterologous genes in expression systems: the role of tRNA. Biotechnol Prog. 12: 417-422.

Snyder, S.L. \& Sobocinski, P.Z. 1975. An improved 2,4,6 trinitrobenzenesulfonic acid method for the determination of amines. Anal Biochem. 64: 284-288.

Stonkus, V.; Leite, L.; Lebedev, A.; Lukevics, E.; Ruplis, A.; Stoch, J., et al. 2001. Lipases in racemic resolutions. J Chem Technol Biotechnol. 76: 3-8.

Straathof, A.J.J.; Panke, S. \& Schmid, A. 2002. The production of fine chemicals by bio-transformations. Curr Opin Biotechnol. 13: 548-56. 
Svendsen, A. 2000. Lipase protein engineering. Biochim Biophys Acta. 2: 223-238.

Torchilin, V.P.; Maksimenko, A.V.; Smirnov, V.N.; Berezin, I.V.; Klibanov, A.M. \& Martinek, K. 1979 The principles of enzyme stabilization IV. Modification of 'key' functional groups in the tertiary structure of proteins. Biochem Biophys Acta. 567: 1-11.

Tyagi, R. \& Gupta, M.N. 1998. Chemical modification and chemical cross-linking for protein/enzyme stabilization. Biochemistry (Moscow). 63: 334-344.

Ueji, S.; Ueda, A.; Tanaka, H.; Watanabe, K.; Okamoto, T. \& Ebara, Y. 2003. Chemical modification of lipases with various hydrophobic groups improves their enantioselectivity in hydrolytic reactions. Biotechnol Lett. 25: 83-87.

Ulbrich-Hofmann, R.; Arnold, U. \& Mansfeld, J. 1997. The concept of the unfolding region for approaching the mechanisms of enzyme stabilization. J Mol Catal B: Enzym. 7: $125-131$

Uppenberg, J.; Hansen, M.; Patkar, S. \& Jones A. 1994. The sequence, crystal structure determination and refinement of two crystal forms of lipase B from Candida antarctica. Structure. 2: $34-40$

Vallin, M.; Syrén, P-O. \& Hult, K. 2010. Mutant lipasecatalyzed kinetic resolution of bulky phenyl alkyl secalcohols: a thermodynamic analysis of enantioselectivity. Chembiochem. 11: 411-416.

Van Loo, B.; Kingma, J.; Heyman, G.; Wittenaar, A.; Lutje Spelberg, J.H.; Sonke, T.; et al. 2009. Improved enantioselective conversion of styrene epoxides and meso-epoxides through epoxide hydrolases with a mutated nucleophileflanking residue. Enzyme Microb Technol. 44: 145-153.

Van Rantwijk, F.; Lau, R.M. \& Sheldon, R.A. 2003. Biocatalytic transformations in ionic liquids. Trends Biotechnol. 21: 131-138.
Verger, R. 1997. Interfacial activation of lipases: facts and artifacts". Trends Biotechnol. 15 (1): 32-38.

Wang, J.; Do, D.; Chuah, G. \& Jaenicke, S. 2013. Core-Shell Composite as the Racemization Catalyst in the Dynamic Kinetic Resolution of Secondary Alcohols. Chem Cat Chem. 5 (1): 247-254.

Wong, S.S. \& Wong, L-JC. 1992. Chemical crosslinking and the stabilization of proteins and enzymes. Enzyme Microb Technol. 14: 866-874.

Woodley, J.M. 2008. New opportunities for biocatalysis: making pharmaceutical processes greener. Trends Biotechnol. 26: 321-327.

Wynn, R. \& Richards, F.M. 1993. Unnatural amino acid packing mutants of Escherichia coli thioredoxin produced by combined mutagenesis/chemical modification techniques. Protein Sci. 2: 395-403.

Xiong, J.; Huang, Y. \& Zhang, H. 2012. Lipase-catalyzed transesterification synthesis of citronellyl acetate in a solvent-free system and its reaction kinetics. Eur Food Res Technol. 235 (5): 907-914.

Yamashita, H.; Nakatani, H. \& Tonomura, B. 1993. Change of substrate specificity by chemical modification of lysine residues of porcine pancreatic alpha-amylase. Biochim Biophys Acta. 1202: 129-134.

Yu, X-W.; Tang, N-J; Xiao, R. \& Xu, Y. 2012. Engineering a Disulfide Bond in the Lid Hinge Region of Rhizopus chinensis Lipase: Increased Thermostability and Altered Acyl Chain Length Specificity. Plos One, 7 (10): e46388.

Zhang, K.; Diehl, M.R.\& Tirrell, D.A. 2005. Artificial polypeptide scaffold for protein immobilization. J Am Chem Soc. 127: 10136-10137. 